\title{
Mercado del libro y empresas editoriales entre el Centenario de las Independencias y la Guerra Civil española: la editorial Sudamericana
}

\author{
Gabriela Dalla CoRTE ${ }^{1}$ \\ TEIAA/Universitat de Barcelona \\ dallacorte@ub.edu \\ Fabio EsPósITo \\ CONICET/Universidad Nacional de La Plata \\ fabioesposito09@gmail.com
}

Recepción: 30 de marzo de 2009 / Revisión: 28 de septiembre de 2009

Aceptación: 8 de abril de 2010 / Publicación: diciembre de 2010

\begin{abstract}
RESUMEN
Las estrategias comerciales de los libreros y editores españoles para desembarcar en los mercados americanos son analizadas en un contexto signado por las tendencias americanistas en el plano político y las iniciativas regeneracionistas en el económico durante el periodo que va del Centenario de las Independencias hasta la Guerra Civil española. Se abordan algunas de las políticas empresariales editoriales implementadas en Cataluña, el liderazgo ejercido por esta región como epicentro del proyecto hispano, y finalmente las condiciones que permitieron la creación de la editorial Sudamericana en Buenos Aires ante la inminencia del triunfo franquista. Los ejes de estudio son las estrategias editoriales y comerciales; el peso de las asociaciones y corporaciones patronales del libro; y los vínculos tejidos con el sector intelectual argentino en las primeras décadas del siglo XX a través de delegaciones consulares, instituciones culturales y cámaras españolas de comercio.
\end{abstract}

Palabras clave: americanismo, Argentina, Cataluña, editores, editorial Sudamericana, Independencias, libros, guerra civil española, siglo XX.

\section{The Book Market and Publishing Houses between the Centennial of the Wars of Independence and the Spanish Civil War: the Sudamericana publishing house}

\begin{abstract}
The commercial strategies of the Spanish booksellers and publishing houses in the American markets are analyzed in a context distinguished by Americanist trends in the political sphere and "regenerationist" initiatives in the economic field, during the period beginning with the Centennial of the Wars of
\end{abstract}

${ }^{1}$ Trabajo resultado del proyecto "El Centenario de la Independencia de América en el mundo intelectual catalán: proyecto político, celebraciones y simbolismo", Gabriela Dalla Corte (d.), Centre d'Història Contemporània de Catalunya, Departament de la Vicepresidència, Generalitat de Catalunya, 2008 (Exp. 2008/1991). 
Independence and ending with the Spanish Civil War. This paper studies the managerial strategies implemented by the publishing houses of Catalonia, the leadership of this region as epicentre of the Hispanic project, and finally the conditions that allowed the creation of the "Sudamericana" publishing house of Buenos Aires, before the imminence of Franco's victory. The foci of study are the publishing and commercial strategies; the importance of the book associations and management corporations; and the bonds formed with the Argentine intellectual sector in the first decades of the 20th century by means of the consular delegations, cultural institutions and Spanish chambers of commerce.

Keywords: Americanism, Argentina, Books, Cataluña, Independence, Spanish Civil War, Sudamericana publishing house, Publishers, 20th Century.

SUMARIO: 1 . Introducción. 2. Las estrategias comerciales de los editores en el marco del "americanismo". 3. Las corporaciones patronales del libro y la aventura exportadora. 4. La fundación de la editorial Sudamericana. 5. Reflexiones finales. 6. Referencias bibliográficas.

\section{INTRODUCCIÓN}

Desde los humildes libreros que se instalaron durante el siglo XIX en las principales capitales hispanoamericanas, hasta los empresarios que participaron de la creación de algunas de las mayores casas editoras argentinas y mexicanas a fines de la década de 1930, la presencia de libreros y editores españoles en los mercados hispanoamericanos ha sido una constante que ha gravitado en ambas márgenes del océano. En esta aventura, los editores de Barcelona desempeñaron un papel fundamental y definitorio, aunque no excluyente de otras experiencias diseñadas en el universo editorial español. Este trabajo se detiene en las políticas comerciales que los editores catalanes desarrollaron con el propósito de conquistar nuevos mercados en Iberoamérica. Una región que, tan sólo por su peso demográfico, atesoraba un público lector de una enorme proyección. Estos editores tejieron desde fines del siglo XIX un complejo entramado social, político y mercantil articulado desde corporaciones patronales como el Centro de la Propiedad Intelectual o la Cámara del Libro de Barcelona y, sobre todo, desde la Casa de América de Barcelona, que amplió su trama hasta las delegaciones consulares, las instituciones culturales, las entidades creadas por la emigración española en Ultramar (como Casa de Galicia de Montevideo, Casino Español de México, Institución Cultural Española de Buenos Aires) y las cámaras de comercio que los migrantes hispanos desplegaron a lo largo $\mathrm{y}$ a lo ancho del continente americano.

A comienzos del siglo XX, editores, libreros y comisionistas coincidían en subrayar la escasa y debilitada presencia del libro español en los mercados americanos, pese a contar con la ventaja aparente de compartir una lengua y una cultura común con las antiguas colonias. Desde el siglo XIX las editoriales francesas, favorecidas por el prestigio de la lengua y la cultura de ese país entre las elites del llamado "Nuevo Continente", habían afianzado su posición en las repúblicas hispanoamericanas y consolidado una amplia red comercial, incluso con un gran surtido de ediciones en castellano. En 1861, por ejemplo, el catálogo de la editorial Garnier alcanzaba los 540 títulos en español, mientras que la casa Rosa y Bouret ofrecía en 1863 aproximadamente unos mil títulos en este idioma. Pero no sólo los franceses incursionaban en un auspicioso mercado en continuo crecimiento $^{2}$; por esos años también

\footnotetext{
2 FERNÁNDEZ RodríGUeZ, 1999.
} 
es posible encontrar en esas repúblicas devocionarios y libros religiosos de la casa alemana Herder y libros técnicos de la editorial Appleton de Nueva York ${ }^{3}$. Estos editores contaban con cuidados mecanismos de promoción, distribución y crédito -al menos así valorados por sus pares establecidos en Barcelona-, y sus catálogos bibliográficos llegaban a los rincones más distantes del continente 4 .

En contraste, la experiencia americana de los editores españoles no iba más allá de algunas aventuras aisladas implementadas desde mediados del siglo XIX, con pobres beneficios en unos casos y catastróficas consecuencias en otros, pese al interés de sus impulsores por consolidarse en el mercado del libro. Algunos sectores de la intelectualidad española empezaron a considerar la necesidad de acercarse a las antiguas colonias, a fin de impedir que otros países europeos ocuparan el lugar dejado por España en el nuevo continente. Las estrategias comerciales de los libreros y editores españoles, particularmente catalanes, para desembarcar en los mercados americanos merecen una atención especial en este proceso y son analizadas aquí en un contexto signado por las tendencias "americanistas" en el plano asociativo y/o político y las iniciativas "regeneracionistas" en el económico. Argentina sería el país elegido en el contexto de la conmemoración del Primer Centenario de las Independencias 5 , entre otras razones por la numerosa comunidad española radicada en el país ${ }^{6}$, siendo finalmente el espacio en el que tomarían forma significativas empresas editoras, entre ellas la Editorial Sudamericana, precisamente en el instante en que llegaba a su fin la Guerra Civil española con el triunfo franquista ${ }^{7}$.

Desde esta perspectiva, en el presente trabajo nos interesa especialmente el despliegue de acciones empresariales en el mundo editorial en las décadas en que se procuró consolidar a Cataluña como epicentro de aquel proyecto hispano. Consideramos este proceso abordando, en primer lugar, las impresiones dejadas por algunos precursores durante la segunda mitad del siglo XIX e inicios de la siguiente centuria, así como las estrategias comerciales de los editores en el marco del movimiento americanista consolidado al calor de la conmemoración del Primer Centenario de las Independencias. Tomamos en consideración la finalidad de empresas como la Revista Comercial Iberoamericana Mercurio, publicada desde 1901 por el comisionista José Puigdollers Maciá (1866-1908), la cual se encargó de promocionar en sus páginas el libro español en territorio americano hasta 1938; es decir, un año antes de que algunos de los actores que la habían sostenido con su pluma y con su ingenio fundaran en Buenos Aires la editorial Sudamericana. En segundo lugar, el papel desempeñado por las corporaciones patronales del libro durante el periodo que hemos denominado como de la "aventura exportadora", entre ellas el Centro de la Propiedad Intelectual o la Cámara del Libro de Barcelona, cuyas memorias e informes, en su mayoría editados, permiten reconstruir algunos de los mecanismos comerciales des-

\footnotetext{
3 Botrel, 1993; Ceballos Viro, en prensa.

4 FERNÁNDEZ RODRÍGUEZ, 1998.

5 DALla CoRTE, en prensa.

${ }^{6}$ Existen numerosos trabajos sobre la comunidad española en Argentina, por ejemplo, MoYA, 1998; NúÑez SeiXas, 2001; Fernández, 2006; Bernasconi-Frid, 2006; Dalla Corte, 2009. Véase también el relato de los propios actores: CALZADA, 1926; Berenguer CARisomo, 1953.

7 Abellán, 1983.
} 
plegados y los proyectos institucionales y empresariales diseñados. Y, en tercer y último lugar, el contexto de la fundación de la Editorial Sudamericana en 1939 a partir de las estrategias desarrolladas por el grupo empresarial creado en torno a la Compañía Hispanoamericana de Electricidad (CHADE). Presidido por Rafael Vehils, este grupo contó con la estrecha colaboración de una parte del sector intelectual argentino encabezado por Victoria Ocampo y Oliverio Girondo, o del prolífico historiador Emilio Ravignani, cuyo archivo particular permite salvar uno de los principales obstáculos a que nos enfrentamos cuando se analiza el momento y las causas de la fundación de Sudamericana que es la carencia de fuentes documentales específicas de la primera época. A través de los indicios ofrecidos por documentación editada e inédita buscamos destacar el impulso del libro español durante las primeras décadas del siglo XX, observando el proceso empresarial mediante algunas de las tácticas asociativas y corporativas desplegadas en la época especialmente en la Argentina.

\section{LAS ESTRATEGIAS COMERCIALES DE LOS EDITORES EN EL MARCO DEL "AMERICANISMO"}

En la década de 1840 se había producido un importante boom de la edición madrileña representado por la proliferación de bibliotecas económicas como la Biblioteca Universal de Fernández de los Ríos, la colección de Mellado o la Biblioteca Ilustrada de Gaspar i Roig8 ${ }^{8}$. Esta última, por ejemplo, comisionó en 1852 a un pequeño librero de ocasión, Domingo Vigues, que llegó a Buenos Aires como representante de algunas casas catalanas como Llorens Hermanos, Manuel Saurí, Jaime Subirana y Jaime Gaspar, entre otros. Eran intentos todavía incipientes pero que abrirían un nuevo espacio; así, frente a las limitaciones del debilitado mercado interno español, el de las repúblicas hispanoamericanas se presentaba para los editores españoles como un horizonte prometedor, pues se trataba de un mercado anexo derivado que no suponía una producción particular u orientadora ${ }^{9}$. La correspondencia que Vigues mantuvo en esos años, tanto con sus superiores como con su familia, permite trazar un panorama del comercio de libros en una ciudad como Buenos Aires. De acuerdo a su relato, Vigues abrió un depósito en Buenos Aires y su actividad consistió en colocar obras en comisión entre los libreros de esa ciudad. En el establecimiento también se realizaron ventas al por menor de obras completas y bajo la modalidad de la suscripción. Con 14 librerías y 25 imprentas, el comercio del libro en la capital argentina presentaba un panorama alentador y grandes perspectivas de crecimiento. Sin embargo, la iniciativa comercial no alcanzaba a ofrecer beneficios $\mathrm{y}$, cuando las dificultades se tornaron insuperables, Vigues regresó a Barcelona en 1855. La experiencia de Gaspar i Roig en Argentina, reseñada a través de Vigues, pone de manifiesto los numerosos inconvenientes que debieron afrontar por esos años los libreros españoles en los mercados hispanoamericanos: problemas de organización, elevados costes del transporte, demoras en los envíos, falta de garantías,

8 Martínez Martín, 1991; Infantes-LópeZ-Botrel, 2003.

9 BOTREL, 2003. 
deudas incobrables, así como también el azote de frecuentes conflictos políticos que interrumpían el comercio con las nuevas repúblicas casi por completo.

Aquel panorama adverso y desalentador parece confirmarse con las rocambolescas memorias de Benito Hortelano, quien a poco de arribar a Buenos Aires a comienzos de la década de 1850 intentó comercializar, mediante la modalidad de la suscripción, la Biblioteca Universal de Fernández de los Ríos. El interés despertado por un catálogo moderno y bien surtido hizo que Hortelano alcanzara la nada despreciable cifra de un millar de suscriptores con sorprendente facilidad. Sin embargo, un retraso de casi un año en el envío de las primeras remesas (que debían llegar desde Madrid a Buenos Aires a través del puerto de Lisboa, con el coste adicional que implicaba el transporte terrestre hasta la capital lusitana), sumado a la escasa coincidencia de las obras enviadas con los títulos prometidos, hicieron que buena parte de los suscriptores rechazara los pedidos y exigiera la devolución de los anticipos. En consecuencia, la venta de la Biblioteca Universal de Fernández de los Ríos cayó en un enorme descrédito y desalentó nuevas operaciones durante años. Sobre este tema recuerda Hortelano:

Eran los primeros días del mes de enero de 1852 y hacía once meses que yo había librado a Madrid, a la orden de Fernández de los Ríos, editor de la Biblioteca Universal, cuatro mil duros para que me remitiese las suscripciones que le pedía. Había yo dado órdenes para que las remesas llegaran con toda regularidad, como las de Francia e Inglaterra; que me dirigiesen mensualmente, por la vía de Lisboa, todas las entregas que se hubiesen publicado en el mes, para de este modo hacer yo el reparto a los suscriptores, como lo hacía El Correo de Ultramar. Creo que nadie pueda calificar de descabellado este plan; pero, para mi desgracia, lo fue. Fernández de los Ríos remitió a Lisboa la primera remesa, consistente en 42 grandes cajones. Pero una fatalidad o una mala fe del corresponsal de Lisboa y mala disposición de Fernández hizo que hasta los ocho meses no llegasen a mi poder las cartas de aviso y facturas de la remesa. Escribí furioso a Ríos increpándole su conducta cuando a los ocho meses recibo sus cartas y facturas avisándome la remisión de mi pedido a Lisboa, de donde debió haber salido en el paquete en junio. Esto vino a confundirme, porque los cajones debían estar en mi poder hacía dos meses. En estas preguntas y respuestas pasaban los meses y los suscriptores desconfiaban y muchos me exigieron la devolución de lo anticipado. Por fin al terminar el mes de enero de 1852 llegó el bergantín holandés Oscar procedente de Lisboa con los 42 cajones de libros. Cuando pedí a Ríos 1.000 suscripciones de la Biblioteca, iban ya publicadas algunas novelas y estaban en publicación otras. No tenía el número de ejemplares que me pedía y solo me remitió 430 ejemplares de cada obra. Ocho meses tardó en llegar la segunda remesa y en lugar de mil vinieron 300, y en vez de novelas e historias que era lo ofrecido remitió cuatro secciones que no se habían ni anunciado aquí ni pedido por mi, y eran 300 obras de Medicina, 300 de Historia Natural, 300 de Educación, y 450 biblias. Todo incompleto y obras tan largas que tardaría dos o tres años para concluirlas ${ }^{10}$.

Ambas iniciativas tuvieron en común las limitaciones de una pobre organización comercial, que se tradujo en una escasa previsión de los problemas, demoras en los

10 Hortelano, 1936, pp. 194-195. 
envíos, incumplimientos de los contratos firmados, dificultades en los cobros, un margen estrecho en las posibilidades de ofrecer crédito a los intermediarios, así como un preocupante desconocimiento de los gustos y los comportamientos de un mercado que sólo en apariencia resultaba semejante al peninsular. Mediante intentos aislados, esfuerzos desproporcionados y con resultados desalentadores, la aventura expansionista de los editores españoles en América ofrecía en el siglo XIX más sinsabores que alegrías en una desigual carrera a lo largo de un territorio que creían controlar, pero que finalmente les habría resultado peligrosamente desconocido. De acuerdo con los datos manejados por el editor catalán Pablo Riera y Sans, miembro de la junta directiva del Institut Català de les Arts del Llibre, a fines del siglo XIX España participaba con un escasísimo $3 \%$ en el mercado del libro en Hispanoamérica, muy por debajo de las ediciones propiamente norteamericanas, francesas, inglesas y alemanas, que dominaban los mercados de la región ${ }^{11}$. Esta situación coincidió con otro fenómeno de igual importancia: España había mantenido prácticamente interrumpido su diálogo con las nuevas repúblicas americanas hasta mediados del siglo XIX, y recién hacia fines de la década de 1860, cuando abandonó definitivamente sus sueños de reconquista luego de la guerra con Chile y Perú (1865), se consolidó el lento camino de la normalización diplomática que se había iniciado tenuemente con el Tratado de Paz y Amistad firmado con México en 1836, y finalizaría en 1904 con el reconocimiento de Panamá12.

Pero será entre finales del siglo XIX e inicios de la centuria siguiente cuando los editores procuren canalizar sus ímpetus expansionistas. En 1892, como parte de las celebraciones del IV Centenario del Descubrimiento ${ }^{13}$, tuvieron lugar en Madrid encuentros de distinta índole, entre los que destacaron el Congreso Pedagógico Hispano-portugués-americano, encabezado por Rafael María de Labra (1840-1918), o el Congreso Literario Hispanoamericano, organizado por la Asociación de Escritores y Artistas Españoles. Por entonces, el "problema del libro español en América", esto es, el escaso protagonismo de los libreros y editores españoles en un mercado dominado por las casas editoras francesas, alemanas y norteamericanas, ya aparece con sus perfiles claramente definidos. En tal sentido, el Congreso Literario Hispanoamericano incluyó en su temario el análisis de

[...] los medios prácticos conducentes al desarrollo del comercio de libros españoles en América y libros americanos en España, así como la de obras artísticas, organizando empresas editoriales, bibliotecas, giro consular y representaciones recíprocas entre todos los países de origen español ${ }^{14}$.

Esto comprendía un análisis de los factores que obstaculizaban su crecimiento, como el costo del transporte y las tarifas postales, los aranceles aduaneros, la ineficiente organización consular, así como también una serie de medidas destinadas a su superación, como la formación de un sindicato de editores y libreros, la implemen-

11 RIERA I SANZ, 1901, p. 4.

12 RAMA, 1982.

13 Bernabeu Albert, 1987 y 2007.

14 Asociación DE Escritores y ARTistas Españoles, 1893, p. 56. 
tación de un servicio de corresponsales, la fundación de agencias y sucursales en el territorio americano, y la eficaz utilización de las sociedades culturales creadas por los emigrantes españoles en las repúblicas americanas.

El gremio de editores no desaprovechó la oportunidad que este foro americanista le ofrecía para alzar su voz en defensa de sus intereses. En su representación acudió el escritor y publicista Rafael Gutiérrez Jiménez con una propuesta para recuperar los mercados del libro de ultramar. Fervoroso partidario de la difusión del libro español en Hispanoamérica, su propuesta contemplaba la renovación de las pautas organizativas del sector, así como la sugerencia de que libreros y editores formasen asociaciones patronales a fin de afrontar con éxito una empresa de la magnitud de la conquista de los mercados americanos:

La causa, pues, determinante de la victoriosa competencia que se hace a nuestros libros, ni consiste en la mayor facilidad en la producción del texto, ni en la economía absoluta de la reproducción de ejemplares: consiste exclusivamente en la gestión editorial. La industria de editar libros está inmensamente más desarrollada en el extranjero que en España: las empresas disponen allí de recursos que están en desproporción colosal con los nuestros, y sobre todo, la propaganda y distribución de ejemplares al alcance del comprador, cuenta allí con elementos de una magnitud incomparablemente superior a la nuestra. Esta, y la falta de casas españolas que se dediquen preferentemente al negocio de exportación de libros, es la razón capital de que no vendamos libros en América ${ }^{15}$.

El diagnóstico de Gutiérrez Jiménez era inequívoco: la escasa presencia del libro español en América se debía a problemas de comercialización. Añadía además que, a pesar de los fuertes vínculos lingüísticos y culturales, los libros de los escritores americanos, que deberían tener en España un mercado natural de importancia tanto para el consumo interno como para el abastecimiento de toda Europa, difícilmente se encontraban en las principales librerías españolas si no llegaban a través del mercado de Leipzig. En otras palabras, Gutiérrez Jiménez puntualizaba que la falta de contacto comercial entre España y América hacía que los autores americanos permanecieran desconocidos en la Península, con excepción de los que ingresaban por intermedio de los libreros alemanes. Esto no significa que Gutiérrez Jiménez tuviera como principal objetivo poner las obras de los autores americanos al alcance de los lectores españoles. Lo que proponía era acaparar su producción para distribuirla en el continente americano y en el resto de Europa, así como también negociar los contratos de traducción a otras lenguas. No tenía en mente tan sólo exportar libros a América, sino imponer el predominio español sobre un conjunto de mercados nacionales con muy escasas relaciones comerciales entre sí. De manera que a los libreros y editores peninsulares se les abriría la posibilidad de ejercer de promotores e intermediarios de las producciones intelectuales de las nuevas repúblicas americanas y adueñarse del mercado de las traducciones del y al castellano.

Para llevar a cabo esta tarea, Gutiérrez Jiménez sugirió en su obra publicada en 1893 la creación de nuevas empresas editoriales concentradoras de la importación y

15 GutiérReZ JiMÉNEZ, 1893, p. 8. 
la exportación de libros, la fundación de bibliotecas populares en España y América, la puesta en marcha de un servicio de corresponsales, la instalación de depósitos internacionales de cambios de libros, el estímulo de la propaganda, la implementación de un sistema de giros y cobros y el bosquejo de un estatuto para una Asociación Internacional de Escritores Españoles y Americanos. En resumen, una modernización profunda de la gestión editorial ${ }^{16}$. Formulado a fines del siglo XIX, este modelo de expansión de Gutiérrez Jiménez que proponía centralizar la distribución mediante depósitos ubicados físicamente en América, otorgar gran importancia a las traducciones y concebir a Hispanoamérica como una gran plaza comercial conformada por mercados nacionales con algunos rasgos diferenciales y otros comunes entre sí, no se hizo realidad, pero su ideario persistió como una aspiración que sería retomada en más de una oportunidad por las elites intelectuales y empresariales, cada vez que las circunstancias internacionales alentaran la aventura exportadora ${ }^{17}$.

El americanismo español, como ideario y movimiento asociativo, tomó fuerza en los primeros años del siglo XX al calor de instituciones semioficiales madrileñas encabezadas por la Unión Iberoamericana, que procuraron imponerse como las interlocutoras privilegiadas ante los organismos estatales ${ }^{18}$. El momento era propicio tanto para América como para España: se preparaban las celebraciones para unos, conmemoraciones para otros, del primer Centenario de las Independencias ${ }^{19}$. Corporaciones y asociaciones aspiraban a auxiliar al gobierno en sus relaciones con las repúblicas latinoamericanas y nutrían una política de gestos diplomáticos ${ }^{20}$. En el ámbito asociativo el americanismo comprende también un conjunto de estrategias que a lo largo de las diferentes regiones del Reino intentaron articular principalmente los intereses de los "hombres de negocios", desplegando políticas de marcado cuño mercantil. El proyecto implementado en Barcelona, y sustentado específicamente por exportadores y comisionistas, tomó forma a partir de la guerra de 1898 que desencadenó una fuerte corriente de inquietud y el deseo de regenerar el país mediante un proyecto de modernización económica basado en el desarrollo industrial y en la exportación. Recuperar la presencia española en América se instaló con la urgencia de una necesidad en numerosos grupos de intelectuales, empresarios y comerciantes de Barcelona a comienzos del siglo $\mathrm{XX}^{21}$.

Al mismo tiempo, las ideas americanistas arraigaron con fuerza en la ciudad, en cuyo puerto convergían intereses mercantiles con los ojos puestos en los mercados de ultramar que explican el creciente éxito que tendría la Revista Comercial Iberoamericana Mercurio desde 1901. Ocho años después, muy poco antes de la Semana Trágica, Frederic Rahola i Trèmols, por entonces secretario de la corpora-

16 GUTIÉRREZ JiMÉNEZ, 1893.

17 EsPósito, 2010.

18 NúÑez SeiXas, 1999; Naranjo - Puig-Samper - Luque, 2002; Cagiao, 2004; Cagiao-Rey Tristán, 2005; Domingo ACEBRÓn, 2005; VÉLEZ, 2007; PrAdo, 2008.

19 Sobre la presencia hispana en América véase GonZÁlez MarTínEZ, 1992.

20 Dalla Corte-Prado, 2006; Sepúlveda MuÑoz, 1991 y 1994.

21 Siguiendo una línea de análisis que considera la política exterior americanista catalana como "imperialista", véanse los trabajos de: YáÑEz Gallardo, 1985; BeretTa Curi, 1993; Costa Ruibal, 2002; UCELAY DA CAL, 2003. 
ción Fomento del Trabajo Nacional y director de Mercurio, rubricó un artículo titulado "Eslabonando" que se convirtió en la base del proyecto editorial americano. Su objetivo: frenar el avance cultural francés. "Agítense en periódicos y libros multitud de ideas y proyectos, para que el predominio y aun la entera hegemonía del espíritu hispano sea un hecho en aquel mundo nuevo", señalaba Rahola, para quien el proyecto editorial de Miguel Seguí, esto es, los 14 tomos de la Enciclopedia Ilustrada. Diccionario universal con todas las voces y locuciones usadas en España y la América Latina, debía ser considerado el modelo del desembarco hispano ${ }^{22}$.

El momento en que el proyecto americanista tomó verdadera forma fue con la creación de la Casa de América de Barcelona, en 1911, cuando Mercurio pasó a ser el órgano de prensa de la nueva entidad. La asociación privada internacional devino en un instrumento fundamental en la articulación de la red mercantil que sostuvo la expansión empresarial catalana en América, y una de las piezas centrales del proyecto americanista liderado por Francesc Cambó (1876-1947) ${ }^{23}$. Casi en las antípodas del discurso cultural americanista, imperante sobre todo en los círculos más cercanos a las políticas estatales de los que formaba parte, por ejemplo, la Unión Iberoamericana madrileña, Mercurio y la Casa de América afirmaban que el interés mercantil debía ser "la gran palanca de los tiempos modernos"24. En poco tiempo la asociación catalana concentró más de mil socios individuales y empresas, con un enorme peso de editores, impresores, publicistas, libreros, litógrafos, literatos, escritores, papeleros, redactores y directores de revistas y anuarios de temática americanista, que utilizaron los servicios corporativos de la Casa de América de Barcelona hasta el estallido de la Guerra Civil y mantuvieron su membrecía incluso durante el franquismo. Así, interesa destacar que hubo un gran número (30) de afiliaciones en los años 1911/1913, es decir, antes de la Primera Guerra Mundial; una segunda afiliación con un importante número (14) de las llamadas "bajas forzadas" no voluntarias producidas durante el inicio de la Guerra Civil; y, ya en el marco del gobierno franquista, un tercer momento de interés de 9 empresarios del mundo editorial involucrados en la actividad editorial por contar con el apoyo de la entidad en el continente americano: Vergara, Roma, Reverte, Planeta, Juventud, Éxito.... Los siete miembros restantes fueron editores que mantuvieron su membrecía desde 1911 hasta 1980, cuando la junta directiva de la Casa de América decidió fusionarse con la delegación catalana del Instituto de Cultura Hispánica. Pese al claro predominio de los capitales españoles en la vida y funcionamiento de la asociación americanista, destacamos la presencia del ecuatoriano Alfredo Flores Caamaño; del argentino Gustavo Draeger, que según nuestros datos residió en Barcelona al menos hasta el año 193425; del mexicano Santiago Galas; del francés Raúl Massé; del cubano Diego Ruiz Escobedo; de la compañía ítalo-española Vecchi y Ramos..., todos ellos dedicados a la incentivación del mercado del libro. El Cuadro 1 procura identificar la composi-

22 Rahola I TRÈmols, 1909, p. 1950. Rahola era, por entonces, director de Mercurio, habiendo incorporado poco antes a Rafael Vehils i Grau Bolívar como miembro estable.

23 De Riquer I Permanyer, 1997.

24 Dalla CORTE, 2005, p. 54.

25 La Vanguardia, 4-I-1934, p. 10, con información de la cita del Ayuntamiento de Barcelona a Gustavo Draeger. 
ción de este grupo a partir de la documentación privada de la asociación, observando la participación, en diferentes momentos y con distinta duración entre 1911 y 1980, de 14 editores y 16 editoriales, un editor y librero pontificio, tres editores litógrafos, seis impresores, un periodista, dos libreros, cinco escritores, un fabricante de películas, un comerciante dedicado al papel, tres redactores y administradores de revistas americanistas y un agente de publicaciones, fusionando todos ellos la producción y la comercialización del libro destinado a América.

\section{Cuadro 1: Socios individuales y razones sociales de la Casa de América de Barcelona dedicados a la actividad editorial (1911-1980) ${ }^{26}$}

\begin{tabular}{|c|c|c|c|}
\hline Nombre del socio individual/empresa & $\begin{array}{c}\text { Periodo } \\
\text { membrecía }\end{array}$ & Tipo membrecía & Actividad \\
\hline 1.- José ARIZA ABALO & $1911 / 1913$ & Fundador & Impresor \\
\hline 2.- Antonio F. BASTINOS & $1912 / 1913$ & Numerario & Editor \\
\hline 3.- Juan BLASI & $1911 /-$ & Fundador & Editor \\
\hline 4.- José BOSCH OLIVERO & $1953 /-$ & Numerario & Librero \\
\hline 5.- Alfonso CABOT PUIG & $1912 /-$ & Fundador & Fabricante películas \\
\hline 6.- Gustavo DRAEGER & $1911 / 1913$ & Protector & $\begin{array}{l}\text { Director América Latina } \\
\text { (argentino) }\end{array}$ \\
\hline 7.- José ESPASA & 1916/1930-1936 & Numerario & Editor \\
\hline 8.- José ESPASA e Hijos & $1911 / —$ & Protector & Editor \\
\hline 9.- Dr. FALGAR & $1913 /-$ & Fundador & Literato \\
\hline 10.- Santiago GALAS & 1926/1930-1936 & Numerario & $\begin{array}{l}\text { Comerciante del papel } \\
\text { (mexicano) }\end{array}$ \\
\hline 11.- Luis GILI & $1912 /-$ & Fundador & Editor \\
\hline 12.- Gustavo GILI ESTEVE & $1977 / 1980$ & Protector & Editor \\
\hline 13.- Gustavo GILI I ROIG & $1912 / 1980$ & Protector & Editor \\
\hline 14.- Alfredo FLORES CAAMAÑO & $1912 / 1913$ & Numerario & Literato (ecuatoriano) \\
\hline 15.- Sebastián GOMILA & $1911 / 1911$ & Numerario & $\begin{array}{c}\text { Redactor en jefe de América } \\
\text { Latina } \\
\end{array}$ \\
\hline 16.- Manuel HENRICH GIRONA & $1911 /-$ & Numerario & Impresor y editor \\
\hline 17.- Manuel MAUCCI & $1911 / 1930-1936$ & Vitalicio & Editor (italiano) \\
\hline 18.- Raúl MASSÉ & $1911 /-$ & Fundador & $\begin{array}{l}\text { Profesor de lenguas } \\
\text { (francés) }\end{array}$ \\
\hline 19.- R. MOLERO & $1914 /-$ & Numerario & Litógrafo \\
\hline 20.- Francisco de A. PÉREZ CORONEL & $1912 /-$ & Numerario & Hacendado y escritor \\
\hline
\end{tabular}

26 Fuentes: Libros de altas y bajas y comprobantes de pago de cuotas de socios de la Casa de América de Barcelona (1911-1980), en Biblioteca del Pavelló de la República (UB) y Casa Amèrica Catalunya, Barcelona. 


\begin{tabular}{|c|c|c|c|}
\hline 21.- Juan PÉREZ RIBAS & $1912 / 1913$ & Numerario & Editor \\
\hline $\begin{array}{l}\text { 22.- Fernando PERIQUET } \\
\text { ZUAZUABAR }\end{array}$ & $1911 / 1913$ & Fundador & Publicista \\
\hline 23.- José PORTER & $1949 /-$ & Numerario & Librero y editor \\
\hline 24.- Diego RUIZ ESCOBEDO & $1913 / 1914$ & Numerario & Literato (cubano) \\
\hline 25.- J. RUIZ ROMERO & $1925 / 1930-1936$ & Numerario & Editor \\
\hline 26.- D. SERRA FERRÚS & $1912 / 1912$ & Numerario & Litógrafo \\
\hline 27.- Pablo SOPENA & $1911 /-$ & Numerario & Editor \\
\hline 28.- Ramón SOPENA & $1911 /-$ & Fundador & Editor \\
\hline 29.- Ricardo SOPENA & $1911 /-$ & Numerario & Editor \\
\hline 30.- Eugenio SUBIRANA & $1912 / 1930-1936$ & Fundador & Editor y librero pontificio \\
\hline 31.- J. THOMAS & $1911 /-$ & Numerario & Editor (litógrafo) \\
\hline 32.- E. THOMAS & $1911 /-$ & Numerario & Editor (litógrafo) \\
\hline 33.- José María TORRES & $1911 / 1913$ & Fundador & $\begin{array}{c}\text { Agente publicaciones } \\
\text { americanas }\end{array}$ \\
\hline 34.- Israel VÁZQUEZ GENER & $1911 /-$ & Numerario Iniciador & Periodista \\
\hline 35.- Rafael VEHILS I GRAU BOLÍVAR & $1911 / 1959$ & Vitalicio & $\begin{array}{c}\text { Publicista, director Casa de } \\
\text { América y Revista Mercurio } \\
\text { (cubano, uruguayo) }\end{array}$ \\
\hline 36.- Mariano VIADA & 1911/1930-1936 & Numerario & $\begin{array}{l}\text { Administrador Revista } \\
\text { Mercurio } \\
\end{array}$ \\
\hline 37.- Oliva de VILANOVA & $1915 / 1930-1936$ & Numerario & Editor \\
\hline $\begin{array}{l}\text { 38.- Anuarios Bailly-Bailliere y Riera } \\
\text { Reunidos S.A. }\end{array}$ & 1918/1930-1936 & Numerario & Editorial \\
\hline 39.- Araluce Casa R.de S. N. & $1920 /-$ & Numerario & Editorial \\
\hline 40.- Artes Gráficas L. Fragine & $1925 / 1966$ & Numerario & Impresor \\
\hline 41.- Éxito S.A & $1950 / 1978$ & Numerario & Editorial \\
\hline 42.- Gustavo Gili S.A. & $1912 / 1978$ & Protector & Editorial \\
\hline 43.- Juventud S.A. & $1946 / 1970$ & Numerario & Editorial \\
\hline 44.- Manuel Maucci Lot & $1911 /-$ & Numerario & Editorial \\
\hline 45.- Montesa S.A & $1960 / 1966$ & Numerario & Editorial \\
\hline 46.- Monteso & $1954 / 1978$ & Numerario & Editorial \\
\hline 47.- Planeta & $1965 / 1966$ & Numerario & Editorial \\
\hline 48.- Ramón Sopena S.A. & $1911 / 1977$ & Numerario & Editorial \\
\hline
\end{tabular}




\begin{tabular}{|c|c|c|c|}
\hline 49.- Reverte S.A. & $1948 /-$ Numerario & Editorial \\
\hline 50.- Roma & $1969 / 1978$ & Numerario & Editorial \\
\hline 51.- Roma Infantiles & $1948 / 1966$ & Numerario & Editorial \\
\hline 52.- Rudolf Mosse S.A. & $1926 / 1930-1936$ & Numerario & Editorial \\
\hline 53.- Vergara S.A. & $1959 / 1970$ & Numerario & Editorial \\
\hline 54.- Herederos de Serra y Rusell & $1911 / 1930-1936$ & Numerario & Editores/impresores \\
\hline 55.- Montaner y Simón & $1912 /-$ & Fundador de número & Editores \\
\hline 56.- Montaner y Simón & $1923 / 1930-1936$ & Numerario & Editorial \\
\hline 57.- Salvat Editores S.A. & $1911 / 1978$ & Numerario & Impresores \\
\hline 58.- Serra Hermanos y Russell & $1911 /-$ & Fundador & Impresores (ítalo-español) \\
\hline 59.- Vecchi y Ramos Cía. & $1913 /-$ & Fundador & Editores \\
\hline 60.- Viuda de Luis Tasso Serra & $1923 / 1930-1936$ & Numerario & . \\
\hline
\end{tabular}

\section{LAS CORPORACIONES PATRONALES DEL LIBRO Y LA AVEN- TURA EXPORTADORA}

Los mercados hispanoamericanos son el origen de la prosperidad de algunas casas barcelonesas como la de Emanuele Maucci (1850-1937), un editor que pasó una fructífera temporada en América y abrió una librería en Buenos Aires y otra en México que dejó en manos de parientes, las cuales fueron verdaderas cabeceras para colocar en el continente casi un tercio del millón de ejemplares de libros baratos y de ínfima calidad que salían anualmente de sus talleres de la calle Mallorca de Barcelona durante los primeros años del siglo $\mathrm{XX}^{27}$. Ramón Sopena, por su parte, llevó adelante buena parte de su expansión comercial gracias al lucrativo contrato suscrito en 1901 con el diario La Nación de Buenos Aires, que le permitió imprimir en sus flamantes talleres de la calle Provença los 872 títulos de la Biblioteca de La Nación a lo largo de casi veinte años, a razón de un título por semana en ediciones de 20.000 ejemplares $^{28}$. Pablo Salvat (1872-1923), finalmente, es otro de los editores que basó sus ventas en los mercados ultramarinos: una vez inauguradas sus modernas instalaciones, envió a sus dos hermanos menores a un extenso periplo por América, que comenzó en 1912 en Santo Domingo y concluyó dos años después en el Río de la Plata, con el propósito de aumentar las ventas, regular el precio de la mercadería, evitar las ediciones "piratas" y asegurar el cobro de los productos colo-

27 LLANAS, 2005.

28 En 1917 Sopena inaugura la línea de los diccionarios, de los cuales la empresa afirma haber hecho tiradas de hasta cien mil ejemplares; véase SOPENA, 1929. 
cados. Pero también el viaje serviría para diseñar la producción futura. Por esa razón los hermanos Salvat debieron recoger datos acerca de la bibliografía hispanoamericana, así como seleccionar obras y autores, especialmente para la Sección Medicina, uno de los puntos fuertes de la editorial catalana. Este viaje impactó en las ventas y también en la renovación del catálogo, que incorporó autores americanos del gusto y el interés de los nuevos lectores de ultramar ${ }^{29}$. Desde esta perspectiva, primero Mercurio y luego la Casa de América de Barcelona, de la que la revista se convirtió en medio de publicación, estimularon, apadrinaron y/o complementaron gran parte de las gestiones de los editores catalanes para fortalecer los mercados americanos del libro escrito en español. No es casual, entonces, que el sector editorial catalán descubriese definitivamente en América el verdadero horizonte de su producción de la mano del mundo asociativo, apuntando hacia allí sus esfuerzos en todos los niveles del mercado del libro, desde las novelas baratas hasta los diccionarios enciclopédicos y los libros técnicos, fundándose en el hecho de compartir una lengua común. Las experiencias asociativas y particulares conducirían al diseño de la gestión de las corporaciones patronales y al inicio del periodo que hemos llamado de la "aventura exportadora".

Desde sus inicios en 1911, la Casa de América de Barcelona incluyó en su agenda la exportación de libros y colaboró activamente en las gestiones de los editores catalanes organizados en torno al Centro de la Propiedad Intelectual y de la Cámara Oficial del Libro de Barcelona, fundada esta última hacia 1918. La asociación privada internacional ofreció sus instalaciones como sede de las actividades de la Cámara Oficial del Libro barcelonesa, y emprendió negociaciones ante el gobierno en defensa directa de los intereses del mundo editorial, como la solicitud de implementación del paquete postal o las negociaciones en la Junta de Aranceles, ente otras. Diversos directivos de la Casa de América desempeñaron funciones similares en aquellas corporaciones dedicadas específicamente a promocionar la exportación del libro; Mariano Viada i Luch, por ejemplo, presidió la asociación en los años 1919 a 1924 y dirigió al mismo tiempo la Cámara Oficial del Libro de Barcelona entre 1921 y 1926. Asimismo, gran parte de las editoriales involucradas en la Casa de América (Montaner y Simón S.A., Salvat Editores S.A., Gustavo Gili, Ramón Sopena, Labor S.A.) fundaron en 1929 el Consorcio Nacional de Editores y Exportadores en Barcelona.

Una de las causas de la presencia casi nula del libro español en los mercados hispanoamericanos a comienzos del siglo XX residía en el bajo nivel de organización empresarial del sector, todavía conformado en su mayor parte por empresas familiares dedicadas al comercio de librería o a cargo de talleres artesanales. Para remediar los bajos niveles de competitividad externa, editores y libreros crearon las primeras corporaciones patronales modernas que involucraron específicamente al mundo del libro, distinguiéndose de sus colegas enrolados en el sector más general de las industrias gráficas. En 1900 se fundó el Centro de la Propiedad Intelectual en Barcelona y un año más tarde la Asociación de Librería en Madrid. Ambas asociaciones patronales que formaban parte de la estrategia diseñada para alcanzar mayores niveles de

${ }^{29}$ En el catálogo de 1915 se pueden apreciar 29 títulos nuevos en prensa para la Sección Medicina, lo que indica claramente el dinamismo de la empresa; CASTELLANO, 2005, p. 107. 
organización y penetrar en los mercados americanos, denunciaron de inmediato las dificultades para competir internacionalmente (ediciones clandestinas, aranceles postales elevados, servicios de fletes extremadamente lentos), además de bregar por un mayor protagonismo de las editoriales españolas en ferias y exposiciones internacionales. Aquellas dos entidades trataron de conciliar estrategias conjuntas para implementar una política del libro. De este modo, en 1909 tuvo lugar en Barcelona la Primera Asamblea Nacional de Libreros y Editores para abordar la reforma de la Ley y Régimen de Propiedad Intelectual y analizar los obstáculos que dificultaban la exportación de libros a los mercados americanos ${ }^{30}$. Dos años más tarde, la Segunda Asamblea Nacional de Libreros y Editores, celebrada en Valencia, aprobó la creación de una Sociedad de Librería para organizar conjuntamente la venta del libro español en América, aunque este ensayo nunca se puso en marcha ${ }^{31}$. Los debates y relatos que nos han dejado los actores indican que entre 1909 y 1911, es decir, cuando finalmente se gestó la Casa de América de Barcelona, el sector empresarial, reunido primero en Barcelona y posteriormente en Valencia, estaba profundamente interesado en hacer del libro el instrumento de la renovación y modernización de la economía peninsular.

La Primera Guerra Mundial, con la retirada de las naciones beligerantes de las plazas hispanoamericanas, ofreció una gran oportunidad para los editores españoles ${ }^{32}$. El incremento de la producción de libros en España durante los años del conflicto bélico -se pasó de 3.438 títulos en 1910 a 4.832 en 1915 para disminuir a 1.305 en 1919- no puede explicarse sin aludir a la notable penetración en el mercado hispanoamericano que, según la Cámara del Libro de Barcelona cuya singularidad analizamos más abajo, alcanzaba a absorber una buena parte de la producción. Esta Cámara calculó que el promedio anual de las exportaciones para el quinquenio 19161920 fue de 12 millones de pesetas y que en la década de 1920 alcanzó los 20 millones. A su juicio, y según datos estadísticos que no podían ser totalmente fiables, España exportaba al continente americano en esos años el $50 \%$ de su producción editorial ${ }^{33}$.

Consciente de que la aventura americana sería imposible sin una fuerte organización empresarial que la respaldase, el editor Gustavo Gili (1868-1945), uno de los miembros más destacados de la Casa de América de Barcelona, presentó en la Conferencia de Editores Españoles y Amigos del Libro, celebrada en la ciudad condal el 8 y 9 de junio de 1917, el proyecto de fundación de una Cámara del Libro que tuviese por objeto gestionar ante las autoridades una serie de medidas en pos de la conquista de los mercados americanos, como la reducción del franqueo postal, la disminución de los aranceles aduaneros, el mejoramiento de los fletes marítimos, entre otros acuerdos. Esta Cámara del Libro, según Gili, aunaría de manera estrecha los intereses de editores, autores y libreros. Sus competencias incluían también:

30 Sobre los debates sustentados a lo largo de esta primera reunión sugerimos la consulta de Asamblea Nacional de Editores y Libreros, 1909.

31 Sobre los debates sustentados en este encuentro sugerimos la consulta de AsAMBLEA NACIONAL DE EDITORES Y LIBREROS, 1911.

32 Larraz Elorriaga, 2007.

33 Sugerimos la consulta de los datos ofrecidos por la CÁmara Oficial del libro de BARCELona, 1923, p. 63. 
Fomentar la expansión del libro español y el progreso de las artes gráficas; interesar de los gobiernos cuantas medidas se juzguen oportunas para el desenvolvimiento de la cultura por medio del libro y estimular con igual propósito las relaciones hispanoamericanas; pedir a los gobiernos el establecimiento de líneas de navegación directas entre España y América y el servicio de paquetes postales a precios reducidos y en buques españoles; influir en que se consiga una organización consular más perfecta; gestionar rebajas en el franqueo de los libros para América, aun sin reciprocidad y en paquetes de tres kilos por lo menos; obtener la supresión de los derechos de Aduana para los libros hispanoamericanos de los países que nos concedan igual franquicia arancelaria; fomentar el intercambio intelectual con los autores americanos; fomentar la producción de pastas para la manufactura de papel y estimular la fabricación de papel de edición; conseguir del gobierno que la cámara del Libro tenga representación propia en la Junta de Aranceles; gestionar la revisión de los tratados de propiedad Intelectual celebrados por España y la celebración de otros nuevos con aquellos estados de lengua española con los que no tenemos aun convenios; estimular el patriotismo de los autores para que no publiquen sus obras en colecciones extranjeras por fútiles razones de vanidad; instituir una fiesta anual del libro; formar agentes viajeros que visiten los países de lengua española para facilitar a los socios datos referentes a los mercados hispanoamericanos; crear escuelas de librería; gestionar la inclusión de conocimientos de geografía historia y literatura de los países iberoamericanos en el Bachillerato; organizar concursos con premios para autores y editores; publicar bibliografías; facilitar la propaganda de libros; gestionar del banco de exportación el descuento de letras sobre América; pedir a concesión del franqueo concertado para la Península; organizar congresos y ferias del libro en España y América; editar el Boletín de la Cámara del libro Español ${ }^{34}$.

Como puede observarse, las tareas concebidas para la nueva corporación apuntaban a la exportación de libros a Hispanoamérica. Este proyecto, aprobado por unanimidad, sería la base de la Cámara del Libro de Barcelona, creada en 1918 y oficializada en el año 192235. En estrecha colaboración con la Casa de América de Barcelona (entre otras razones por la constante actuación de las mismas personas en ambas entidades), esta Cámara alcanzó numerosos logros en favor de la exportación de libros, tanto en relación con las tarifas postales y los aranceles del papel, así como en los convenios de protección de la propiedad intelectual. Un caso puntual puede darnos idea de la incidencia de esta corporación: el 13 de noviembre de 1920, por ejemplo, se firmó en Madrid el Convenio Postal Hispanoamericano. En julio de 1921, en calidad de director de la Casa de América, Rafael Vehils inició gestiones ante el Subsecretario de Estado solicitando información sobre la ratificación del convenio. Desde el gobierno se respondió que el convenio había sido aprobado el 13 de febrero de 1921, pero que se esperaban las aceptaciones de los demás países firmantes para ponerlo en vigor. Los editores pretendían que el gobierno español pusiera en vigencia el mencionado convenio sin esperar la reciprocidad del resto de los países hispanoamericanos, para beneficiarse de inmediato con una considerable rebaja en las tarifas postales. Es por eso que Vehils insistió ante el Conde de Colombi, direc-

34 Sobre las propuestas de este grupo liderado por el editor Gustavo Gili, véase GiLI, 1917, p. 17.

35 Martínez Martín - Martínez Rus - SÁnChez García, 2004, pp. 99-113. 
tor del Correo, preguntando sobre la fecha en que se adoptararían las tarifas del convenio referido. Se le comunicó que se estaba esperando la ratificación de España luego de que el resto de los países enviaran sus respectivas aceptaciones. Ante esta situación, Mariano Viada hizo oír el profundo desacuerdo de la Casa de América en una carta firmada el 4 de octubre de 1921, en la que refería que, pese a la falta de acuerdo, algunos países habían puesto en vigencia el convenio. Viada declaró que la "Casa de América cree además que esta interpretación sería altamente beneficiosa para los intereses españoles en América, singularmente los del libro"; y consideraba

[...] urgente dar valor activo a la ratificación, por cuanto pudiera darse el caso, que, de no hacerlo de inmediato, algunos países se desentendiesen del pacto postal aludido, obedeciendo a determinadas sugestiones que se han producido en Ultramar en pro de una Unión Postal americana que, de prosperar conducía naturalmente al abandono de los Convenios hispanoamericanos de $1920^{36}$.

Como resultado de estas negociaciones se proclamó, el 19 de noviembre de 1921, el Real Decreto que puso en vigencia el Convenio Postal de 192037. De inmediato, la Casa de América y la Cámara Oficial del Libro de Barcelona protestaron enérgicamente ante el ministro de la gobernación contra el Real Decreto relativo al Convenio Postal, porque a su juicio "falsea el espíritu y la letra de dicho Convenio perjudicando enormemente los intereses de la cultura hispana" 38 , y pidieron que se pusiera en vigor sin restricción alguna. El corolario de la presión del sector empresarial fue el Real Decreto del 7 de enero de 1922, que modificaba el anterior y ponía en vigencia el Convenio Postal de 1920, dejando a un lado las polémicas restricciones ${ }^{39}$. Este y otros conflictos afrontados por la Cámara del Libro de Barcelona demuestran que fue una de las entidades que, junto con las empresas editoriales, más beneficios extrajo de su pertenencia a la asociación internacional americanista Casa de América de Barcelona ${ }^{40}$.

36 Cámara Oficial del libro de Barcelona, 1922, p. 57.

37 Texto del Real Decreto del 19 de noviembre de 1921 que pone en vigor el Convenio de 1920: "A propuesta de Ministro de la Gobernación de acuerdo con el parecer de mi Consejo de Ministros vengo en decretar lo siguiente: Art. 1.- Se pone en vigor el Convenio Postal firmado en Madrid el 13 de noviembre de 1920 entre España, las repúblicas americanas y Filipinas; Art 2.- La vigencia acordada por el artículo anterior se aplicará a las relaciones postales con los países signatarios que hasta el presente hayan ratificado la puesta en vigor de dicho convenio, pero se extenderá a los demás a medida que se coloquen en una de dichas condiciones; Art. 3.- El Ministro de la Gobernación queda encargado de la ejecución del presente Decreto", CÁmARa Oficial del libro DE BARCElona, 1922, p. 54.

38 Ibidem, p. 59.

39 Real Decreto del 7 de enero de 1922: “A propuesta del Ministro de la Gobernación y de acuerdo con el parecer de mi Consejo de Ministros. Vengo a decretar lo siguiente: Art. $1^{\circ}-$ A partir del $1^{\circ}$ de febrero próximo, se aplicará el Convenio Postal firmado en Madrid el 13 de noviembre de 1920, a las relaciones postales entre España y los países signatarios del mismo, aunque algunos de dichos países no se hallen comprendidos en el alcance del Real Decreto del 19 de noviembre próximo pasado. Art. $2^{\circ}$ - El Ministro de la Gobernación queda encargado de la ejecución del presente Decreto", CÁmARA Oficial del Libro de Barcelona, 1922, p. 66.

40 Dalla CoRTe, 2005. 
Pero las gestiones a favor de beneficios postales no concluyeron aquí. Un año después Vehils obtuvo una enmienda en la Ley del Timbre, que creó un nuevo sello postal de cinco céntimos, con el cual el coste de un paquete de dos kilos enviado a América pasaba de 2,25 a 0,55 pesetas. En suma, la poderosa voz de Casa de América de Barcelona se dejaba oír con fuerza en los pasillos gubernamentales para proteger y estimular el comercio del libro en una estrategia mercantil que se inclinó claramente hacia los mercados americanos. Esta tendencia se verifica una vez más al indagar las posturas de la Casa de América y de la Cámara del Libro de Barcelona en las negociaciones de los nuevos acuerdos sobre los aranceles de importación para el papel. La posición compartida por ambas entidades en la ardua negociación con los fabricantes de papel favoreció a los editores dedicados principalmente a la exportación, en desmedro de los intereses de aquellas casas editoras inclinadas a satisfacer el mercado interno.

En esta línea, la industria del libro gozó de una enorme inserción entre los sectores exportadores prioritarios, por lo cual obtuvo el privilegio de incluir un representante en la estratégica Junta de Aranceles. En 1919, Francesc Cambó, por entonces Ministro de Hacienda, elevó a diez los miembros de la Junta de Aranceles, concediendo un representante al Comité Oficial del Libro. Ese lugar sería ocupado por Rafael Vehils, estrecho colaborador del político catalán, director de la Casa de América y secretario de la Cámara del Libro de Barcelona. Uno de los grandes obstáculos de los editores a finales de la Primera Guerra Mundial residió en el precio del papel, que se había triplicado a causa del aumento de las materias primas y de los fletes. Editores, propietarios de periódicos y fabricantes de papel se vieron enfrentados en un severo conflicto de intereses que amenazó con paralizar el desarrollo del sector. Vehils, junto con Nicolás Urgoiti, artífice de La Papelera Española y director del diario $\mathrm{El} \mathrm{Sol} \mathrm{y} \mathrm{de} \mathrm{la} \mathrm{editorial} \mathrm{Calpe,} \mathrm{fueron} \mathrm{los} \mathrm{encargados} \mathrm{de} \mathrm{redactar} \mathrm{un} \mathrm{convenio}$ arancelario que concedió a las empresas editoriales importantes descuentos en el precio del papel, especialmente en el destinado a los libros de exportación ${ }^{41}$. Como resultado de este convenio se implementó, en 1922, un sistema de bonificaciones para compensar el mayor costo del papel nacional protegido por los aranceles aduaneros, por el cual los fabricantes de papel debían otorgar a los editores un descuento equivalente al $25 \%$ del arancel de importación correspondiente a esa clase de papel, cifra que se elevaba al $40 \%$ si los libros producidos fueran para exportar a Hispanoamérica y al $60 \%$ cuando se exportaran a través de los sindicatos de exportación ${ }^{42}$.

De acuerdo con la versión de la Cámara del Libro de Barcelona, los editores habían solicitado para el papel de edición el mismo régimen arancelario del que gozaba el papel prensa. Sin embargo, este requerimiento no prosperó debido al fuerte proteccionismo sobre la industria del papel, que ya había cedido gran parte de sus intereses a causa de las exitosas presiones del periodismo para importar papel exento de gravámenes fiscales. Los editores debieron conformarse con la obtención de ventajas arancelarias tan solo para la exportación de libros. Es decir, una compensa-

41 Cámara Oficial del libro de Barcelona, 1922, p. 59.

42 MarTínez Rus, 2002, p. 1028; sobre la historia de La Papelera Española y la carrera de Nicolás María de Urgoiti véase CABRERA, 1994 y AUBERT, 2005. 
ción arancelaria por la devolución de los derechos en las materias exportadas. Las gestiones de Vehils obtuvieron una declaración de la Junta de Aranceles que solicitó al gobierno "el desarrollo inmediato de una política sustantiva de fomento del libro español". Ello dio lugar a la Real Orden del 9 de diciembre de 1921 por la cual el Ministro de Hacienda comisionaba a Beltrán y Musitu, Urgoiti y Vehils para el estudio y la propuesta de unas bases de convenio, con la finalidad de conceder descuentos en el precio del papel a las empresas editoriales, especialmente en el papel destinado a libros para la exportación. La consecuencia de aquella Real Orden fue el acta del 24 de diciembre 1921, suscrita por Vehils con el acuerdo del Consejo de la Cámara, que dio lugar al Real Decreto del 17 de febrero de $1922^{43}$.

Aquel convenio garantizó las aspiraciones monopólicas del sector papelero y favoreció a las corporaciones patronales del sector editorial, apuntalando la difusión del libro español en tierras americanas. Pero quedaba un problema por resolver: uno de los grandes escollos que entorpecía la exportación de libros a Hispanoamérica era la existencia de ediciones clandestinas, florecientes al amparo de las dificultades de las comunicaciones entre España y América y del vacío jurídico en relación con la protección de la propiedad intelectual de los autores y los editores españoles en los vastos territorios ultramarinos ${ }^{44}$. Conscientes de tales obstáculos, desde los despachos de Casa de América se luchó por la defensa de los derechos intelectuales, proponiendo la firma de tratados de propiedad literaria con las repúblicas hispanoamericanas. Así, el 20 de noviembre de 1921, Vehils presentó ante el Ministro de Hacienda una moción para promover desde el ámbito gubernamental la constitución de la Unión de la Propiedad Intelectual Hispanoamericana y llevó adelante el proyecto de un Tratado de Propiedad Intelectual con Uruguay aprobado por el Congreso de Diputados en el año $1923^{45}$, precisamente un año antes de establecerse en Montevideo. El tema cobró tal importancia que el Real Decreto del 17 de julio de 1923, que reorganizaba las cámaras de comercio españolas de ultramar, incluyó entre sus propósitos principales dedicar especial atención a la protección de la propiedad intelectual y procurar velar por los derechos de autores y editores. Dispuso, asimismo, designar una comisión especial permanente para los asuntos relacionados con la propiedad intelectual y el comercio del libro español, que actuara como delegación de las cámaras oficiales del libro. De este modo, la década de 1920 inauguró un periodo favorable para la industria editorial española. El crecimiento de la producción fue acompañado por un incremento considerable de los niveles de inversión, una modernización de la gestión comercial y una consolidación de las formas de asociación patronales. Se hicieron oficiales las cámaras del libro de Madrid y Barcelona, y la exportación de libros se convirtió en una preocupación que superó los límites de las corporaciones de editores. El libro fue uno de los productos en los que se apoyó la política de comercio exterior impulsada por los editores, algunos de los cuales, junto con los escritores españoles y catalanes, se propusieron defender el uso y la divulgación de la lengua catalana.

\footnotetext{
43 Cámara Oficial del libro de Barcelona, 1922, p. 20.

44 Sobre las ediciones clandestinas en Hispanoamérica, MARTínEZ Rus, 2000.

45 Cámara Oficial del libro de Barcelona, 1925, p. 45.
} 
En este contexto auspicioso y prometedor, el americanismo catalán no sólo ejerció las más variadas formas de presión sobre los diferentes gobiernos a los fines de obtener beneficios fiscales y protección jurídica en favor del comercio del libro y la consolidación de los mercados hispanoamericanos, si no que sus actividades constituyeron un conjunto de estrategias comerciales que conformaron una verdadera política del libro de largo alcance. Así, Casa de América confeccionó una encuesta que el Ministerio de Estado remitió a los cónsules de ultramar para que éstos elaborasen una memoria de la situación del comercio del libro en cada uno de los países en donde ejercían la representación diplomática. Esta gestión se relaciona con la creación de un Archivo del Libro, complemento del Archivo General de Economía-Casa de América, formado por noticias comerciales americanas de diversa índole, que prestó a la Cámara del Libro una enorme utilidad. Estas memorias consulares fueron la base de la ponencia que la Cámara Oficial del Libro presentó en el foro del Primer Congreso Nacional de Comercio Exterior en Ultramar, organizado en Barcelona por la Casa de América entre marzo y abril de 1923. No resulta extraño que el conjunto de preocupaciones concernientes a la difusión del libro español como los problemas de propiedad literaria, de aranceles y transporte y de propaganda formara parte del temario previsto para ese congreso, que contó con la participación de la casi totalidad de las cámaras de comercio españolas en el exterior. La inserción de la comercialización del libro en ese evento fue un verdadero logro de los exportadores catalanes y en particular de los editores, quienes consiguieron incluir sus intereses dentro de la agenda de las asociaciones empresariales y comerciales españolas de la Península y América.

\section{LA FUNDACIÓN DE LA EDITORIAL SUDAMERICANA}

El grupo de empresarios, hombres de negocios y políticos catalanes enrolados en la Casa de América de Barcelona y articulados a la sombra de la señera figura del líder de la Lliga Regionalista de Catalunya, Francesc Cambó, manifestaron desde los inicios de su organización corporativa un persistente interés en el comercio del libro. Este interés no sólo se debió al hecho de que un buen número de los miembros de la entidad americanista fueran editores; los "hombres de Cambó" veían en general en el sector editorial un campo fecundo para instrumentar políticas culturales y mercantiles que fortalecieran el quehacer político de la Lliga Regionalista, con lo cual no debe extrañarnos que los emprendimientos editoriales acompañaran a sus empresas periodísticas. A nuestro juicio, el caso más paradigmático fue la fundación, en 1917, de la Editorial Catalana bajo la presidencia de Cambó, que fue concebida como un complemento del diario La Veu de Catalunya (1899-1937) para reforzar la influencia social, cultural y política de la Lliga ${ }^{46}$. Resulta significativo que la editorial pasara en 1926 a las manos de Antonio López Llausás (1888-1979), por entonces propietario de

46 Esta editorial tenía como propósito defender y difundir la cultura en lengua catalana. Publicó numerosas revistas, entre las que destacó el magazín D'Aci i d'Allà (1918-1936) y buena parte de su catálogo estaba conformado por una Biblioteca Literaria que procuraba traducir al catalán las grandes obras de la literatura universal y una Biblioteca Catalana encargada de promover los valores autóctonos. 
la Librería Catalonia, que en 1939 sería la persona elegida por Rafael Vehils, mano derecha de Cambó en Buenos Aires, para afrontar la dirección de Sudamericana.

La carrera profesional de Rafael Vehils, director de la asociación americanista internacional Casa de América de Barcelona y de la Revista Comercial Iberoamericana Mercurio $^{47}$, es precisamente un ejemplo de la importancia que cobró el comercio del libro en el proyecto de expansión económica de la élite catalana, y brinda pistas para observar el funcionamiento del tejido mercantil anudado entre Barcelona y el Río de la Plata que sería la base de la creación de Sudamericana. Vehils colaboró estrechamente con Francesc Cambó como diputado a Cortes representando al distrito de Castellterçol, en los años en que el líder de la Lliga Regionalista se desempeñó como ministro de Fomento (22 de marzo de 1918 a 9 de noviembre de 1918) y de Hacienda (del 14 de agosto de 1921 al 8 de marzo de $1922)^{48}$. Fue secretario general de la Cámara Oficial del Libro de Barcelona y vocal de la Junta de Aranceles. En esta última entidad, junto con Nicolás Urgoiti (18691951), elaboró el borrador del convenio que fijaría los aranceles de importación para el papel en España. Fue también miembro del Consejo Superior de Economía, secretario general del Comité de Comercio Exterior y presidente del Sindicato Hispanoamericano de Promoción y Estudios Financieros.

En las décadas de 1910 y 1920, Vehils había realizado dos intensos viajes a América con objetivos distintos: entre 1912 y 1913 intentó fundar un sindicato algodonero catalano-americano con intereses en el Chaco argentino-paraguayo, proyecto que fracasó, entre otras razones, por la declaración de la Primera Guerra Mundial. Entre 1924 y 1925 se estableció temporalmente en Montevideo para dirigir la compañía de tranvías La Transatlántica y fomentar la importación de libros españoles en el continente. Es esta segunda estancia la que expresa el cambio en la orientación de la asociación americanista dirigida por Vehils, y la que le permitió una estrecha colaboración con la Cámara Oficial Española de Comercio fundada en Montevideo. Gracias a su permanencia en la ciudad, Vehils llevó adelante una interesante indagación sobre las posibilidades del mercado editorial hispano en América, que le llevó a publicar la obra sobre el libro en Uruguay en 1927 y a participar en la Conferencia Nacional del Libro de Barcelona.

La residencia definitiva de Rafael Vehils en territorio americano se produjo a partir del año 1927, cuando aceptó dirigir en Buenos Aires la CHADE ${ }^{49}$. Muy pronto se hizo cargo de otros organismos corporativos que le permitieron difundir la ingente

47 Véase el contenido inicial de su proyecto americanista en VeHILs, 1909, p. 2143.

48 En la elección parcial efectuada el 30 de junio de 1918, por ejemplo, Vehils se incorporó con la credencial número 416 desde julio de 1918 hasta mayo de 1919 en sustitución de Cambó quien, por sorteo, pasó a representar al distrito de Barcelona. De un total de 7.867 electores, y con la participación de 4.648 votantes, Vehils asumió como diputado con el número de credencial 253 al obtener 4.481 votos, se convirtió en jefe de gabinete de Cambó, y en el Congreso de Diputados se inscribió como "comerciante". Posteriormente, tras las elecciones del 1 de junio de 1919, obtuvo 3.171 votos de un total de 5.761 y con un padrón de 7.862 electores. Ingresó el 12 de junio de 1919 y su baja se produjo el 24 de julio de 1919 cuando el Tribunal Supremo propuso la nulidad de la elección y fijó una nueva convocatoria; véase VEHILS, 1917-1919.

49 Dalla CorTe, 2006, pp. 528-529. 
actividad editorial hispana: presidió la Institución Cultural Española y la Cámara Oficial Española de Comercio porteñas, argumentando en ambos casos que su objetivo era proteger los intereses comerciales españoles en Argentina. Como presidente de la cámara, Vehils organizó en julio de 1933 la Primera Exposición del Libro Español en Buenos Aires ${ }^{50}$. En realidad, buena parte de los proyectos que Vehils planteó como director de la Casa de América de Barcelona y de Mercurio los implementó en Buenos Aires, pero ya en el contexto de la dirección de la CHADE que, como dijimos, asumió a partir de 1927. Hombre de negocios, gestor cultural, periodista, político y diplomático, la ubicuidad de Vehils muestra claramente el interés que despertaba el libro en la esfera de los grandes negocios españoles, el entramado multifacético sobre el que se apoyaba su comercialización, y la fuerza de la red tejida durante décadas en la capital catalana.

El proceso abierto en 1939 fue muy corto aunque hundía sus raíces en el tejido empresarial editorial previo. Clausuradas en 1939 las posibilidades de regresar a Barcelona y continuar con la dirección de la Casa de América y con la publicación de Mercurio, Vehils se propuso fundar una editorial en la capital argentina con el nombre de Latinoamericana. Apeló a los vínculos tejidos gracias al control de corporaciones, editoriales, revistas y asociaciones ${ }^{51}$. Desde su cargo de director de la CHADE y de la Institución Cultural Española porteña convocó a personalidades de la cultura argentina, como Oliverio Girondo 52 y la directora de la revista Sur, Victoria Ocampo, que acompañaron a Vehils como principales accionistas, y a destacados empresarios de diversa orientación ideológica como Jacobo Saslavsky, Antonio Santamarina, Alejandro Shaw, Eduardo Bullrich, Carlos Mayer y Alejandro Menéndez Behety. Andreu Bausili53, que fuera consejero en el ayuntamiento barcelonés y directivo de la CHADE a las órdenes de Cambó, también asumió acciones de la editorial que fue finalmente bautizada con el nombre de Sudamericana. La nueva empresa editorial buscará canalizar en parte la producción editorial del grupo cata-

50 SAMPERE, 1998.

51 Para analizar esta etapa de Sudamericana acudimos a la documentación que guarda la Colección Emilio Ravignani de la Universidad de Buenos Aires (UBA en adelante), uno de los escasos reservorios que conservan información documental sobre la editorial, ya que el historiador formó parte de ella como accionista. Carta de la Editorial Sudamericana S.A. a Emilio Ravignani. Buenos Aires, 10-II1939. UBA, Colección Emilio Ravignani, Serie 2, Caja 34, Correspondencia (1914-1952); Carta de la Editorial Sudamericana S.A. a Emilio Ravignani. Buenos Aires, 17-XI-1939. UBA, Colección Emilio Ravignani, Serie 2, Caja 36, Correspondencia (1914-1952). Cabe señalar que Sudamericana funcionó como una empresa familiar hasta que fue vendida al grupo editorial alemán Bertelsmann AG en 1997, convirtiéndose en multinacional. La primera sede de la editorial se estableció en el centro de la ciudad de Buenos Aires, en la esquina de Bolívar y Alsina. En 1965 se trasladó al barrio de San Telmo, donde sigue funcionando en la actualidad.

52 La presencia de Oliverio Girondo es significativa si consideramos que por entonces conformaba junto con Jorge Luis Borges la vocalía de la Comisión Argentina de Ayuda a los Intelectuales Españoles, presidida por Francisco Romero, y que contaba con la colaboración de Emilio Ravignani, Norberto A. Frontini y María Rosa Oliver como secretario y pro-secretarios; Carta de la Comisión Argentina de Ayuda a los Intelectuales Españoles a Emilio Ravignani. Buenos Aires, 10-VI-1939. UBA, Colección Emilio Ravignani, Serie 2, Caja 34, Correspondencia (1914-1952).

53 Bausili SAN Romá, 1974. 
lán encabezado por Vehils y Bausili e intentará sustituir el diseño empresarial de Mercurio. A nivel ejecutivo, la primera junta directiva quedó presidida por el argentino Mayer, seguida de Vehils, Saslavsky, Santamarina, Bullrich, Shaw, Bausili, Tito Arata, Enrique García Mérou y Menéndez Behety.

En los hechos, Sudamericana permitió afrontar el exilio de un importante grupo de pensadores y escritores que aprovecharon la creciente producción intelectual que tenía lugar en diversas ciudades latinoamericanas como Buenos Aires, Ciudad de México y San Pablo.

Fue un instrumento más de la gran actividad hispano-argentina desatada a partir de 1939, que se percibió en la multiplicidad de organizaciones surgidas al calor del proceso abierto con la guerra y el exilio ${ }^{54}$ que fijaron su residencia en la calle Bartolomé Mitre 950 donde funcionaban organizaciones no siempre armónicas entre sí, como el Patronato Hispano-Argentino de Cultura ${ }^{55}$, el Centro Republicano Español${ }^{56}$, y las Entidades Ibéricas Republicanas de Buenos Aires ${ }^{57}$.

54 Este proceso no fue exclusivo de Argentina; en Chile, por ejemplo, uno de los países en que más significativamente se viviría la llegada de exiliados de la mano de Pablo Neruda, la comunidad española se dividió entre nacionales y republicanos al estallar la Guerra Civil, formándose organizaciones especiales para realizar acciones de propaganda republicana tales como el Comité de la Cruz Roja Española, el Comité Pro España Republicana, la Alianza de Intelectuales de Chile, en este caso con apoyo de Neruda, o el Directorio General de Instituciones Republicanas Españolas de Santiago; ALMONACID ZAPATA, 2004.

55 El Patronato Hispano-Argentino de Cultura se encargó de publicar los Cuadernos de Cultura Española con trabajos de autores españoles que actuaban en Buenos Aires a favor de la memoria histórica de la Segunda República, entre ellos Rafael Alberti (El poeta en la España de 1931), Ricardo Baeza (Centenario de Emilio Zola), el ex ministro de Justicia de la República española Manuel Blasco Garzón (Gloria y pasión de Antonio Machado), el ex presidente del Consejo de Ministros de la República española Augusto Barcia (La politica de no intervención), Alejandro Casona (Una misión pedagógica-social en Sanabria), Mariano Gómez (Abril de 1931 en Valencia, historia de dos días), Jacinto Grau (Unamuno y la España de su tiempo), el ex Vicepresidente de las Cortes Constituyentes durante la República Luis Jiménez de Asúa (Anécdotas de las Constituyentes), Francisco Madrid (Las últimas veinticuatro horas de Francisco Layret), el embajador español en la Argentina durante la República Angel Ossorio y Gallardo (La guerra de España y los católicos), Manuel Serra Moret (La reconstrucción nacional de España) y José Venegas (Las elecciones del Frente Popular); datos generales en Carta de Tirso Lorenzo a Emilio Ravignani que incluye publicidad de la serie Cuadernos de Cultura Española del Patronato Hispano-Argentino de Cultura. Buenos Aires, 29-IX-1941. UBA, Colección Emilio Ravignani, Serie 2, Caja 39, Correspondencia (1914-1952).

56 El Centro Republicano Español fue presidido entonces por Miguel Servera, R. Martínez Redondo, y ejerció la presidencia accidental Tirso Lorenzo, mientras su sección cultural (Ateneo Pi y Margall) era presidida por Luis Jiménez de Asúa. Se proyectaba como una "contribución de los españoles demócratas y republicanos a la vida institucional argentina". Carta de R. Martínez Redondo, presidente del Centro Republicano Español de Buenos Aires a Emilio Ravignani. Buenos Aires, 3-IX-1941, y carta de Tirso Lorenzo a Emilio Ravignani que incluye programa del ciclo Argentina-España y la declaración de objetivos del Centro Republicano Español. Buenos Aires, 29-IX-1941. Ambas en UBA, Colección Emilio Ravignani, Serie 2, Caja 39, Correspondencia (1914-1952).

57 Cartas de Entidades Ibéricas Republicanas de Buenos Aires a Emilio Ravignani. Buenos Aires, 30IV-1940 y 21-V-1940. UBA, Colección Emilio Ravignani, Serie 2, Caja 39, Correspondencia (1914-1952). 
Todas estas organizaciones estaban en contacto con algunos de los socios fundadores de Sudamericana ${ }^{58}$.

Desde el inicio ejercieron como gerentes de la editorial Julián Urgoiti, que había llegado a Buenos Aires tiempo antes para dirigir la delegación de la Editorial Calpe, y Antoni López Llausàs, que se encontraba exiliado en Francia cuando fue contratado por Vehils. López Llausàs desplazaría de manera inmediata a su mecenas y, además de convertirse en propietario, asumió la dirección de la editorial hasta su muerte, producida en 1979, desluciendo el papel central que tuvo Vehils en el primer año de funcionamiento de Sudamericana ${ }^{59}$. Este giro se explica, en parte, por dos estrategias accionarias y mercantiles asumidas por la junta directiva en el preciso instante en que se declaró la Segunda Guerra Mundial. Una de las tácticas adoptadas por Sudamericana cuando su éxito en el comercio del libro fue amenazado por el conflicto internacional fue la ampliación del capital de la empresa. En efecto, el capital inicial fue de $\$ 374.000$, descompuesto en 36 acciones diferidas de $\$ 500$ cada una (un total de $\$ 18.000$ ), una primera serie de 712 acciones ordinarias por valor de $\$ 500$ cada una (un total de $\$ 356.000$ ), previendo una reducción de capital de $\$ 126.000$ por cuyo importe se emitieron 252 bonos por $\$ 500$ de valor nominal para un potencial rescate. A los pocos meses de echar a andar Sudamericana, los accionistas ampliaron su capital a $\$ 1.000 .000$ mediante la emisión de 13 nuevas series de acciones ordinarias de $\$ 500$ de valor nominal, y sacrificaron sus ganancias del año 1939 para mantener con vida este ensayo editorial. Durante una asamblea general extraordinaria convocada a mediados de 1940 en la sede de la calle Alsina 500, los socios aceptaron la reorganización financiera y la modificación de los estatutos de la sociedad (Cuadro 2). El directorio, tal como reseñan sus acuerdos asamblearios,

[...] se encontró ante el dilema de desarrollar íntegramente su programa editorial, con la inversión de las cuantiosas sumas que ello representaba, o adoptar un criterio de prudencia, aminorando el ritmo de las publicaciones, lo cual implicaba que, aun contando con el buen éxito de los libros, no se podrían cubrir los gastos generales ${ }^{60}$.

Esta difícil situación, sumada a las desavenencias entre sus miembros, muchos de ellos de orientación política conservadora como Luis Duhau, excluyó rápidamente a actores decisivos en los inicios del proyecto editorial, como Alfredo González Garaño, Emilio Ravignani o el propio Rafael Vehils.

58 Martínez Rus, 2003 y 2008; algunos de los exiliados habían pertenecido a la Junta de Ampliación de Estudios (JAE). Sobre la institución véase NARANJO OROVIO, 2007. La intelectualidad hispana diseñó dos organismos que auxiliaron a los republicanos: el Servicio de Emigración de Refugiados Españoles (SERE), presidido por Juan Negrín, y la Junta de Auxilio a los Republicanos Españoles (JARE), que tendrían una gran actuación en el México de Lázaro Cárdenas más que en Argentina en la que, además, en febrero de 1939 el gobierno argentino reconoció el triunfo franquista; Pellegrino Soares, 2007.

59 RIBES, 2008; véase particularmente las obras dedicadas por la nieta de Antoni López Llausàs: LóPEZ Llovet, 2004 y, especialmente, 2006, que recoge la exposición itinerante Literaturas del exilio iniciada en Barcelona en ese año; también QuiJadA, 1991; SCHWARsteIn, 2001.

60 Cartas de la Editorial Sudamericana S.A. a Emilio Ravignani. Buenos Aires, 22-VI-1940 y $13-$ IX-1640. UBA, Colección Emilio Ravignani, Serie 2, Caja 36, Correspondencia (1914-1952). 


\section{Cuadro 2: Accionistas de la editorial Sudamericana en la etapa de su fundación (1939-1940) ${ }^{61}$}

\begin{tabular}{|c|c|c|c|c|c|}
\hline Accionistas & $\begin{array}{c}\text { Acciones } \\
\text { Anteriores }\end{array}$ & Valor (\$) & $\begin{array}{c}\text { Acciones } \\
\text { Ordinarias }\end{array}$ & $\begin{array}{c}\text { Acciones } \\
\text { Diferidas }\end{array}$ & Bonos \\
\hline Carlos MAYER & 10 & 10.000 & 4 & 2 & 14 \\
\hline (i?) SÁENZ & 10 & 10.000 & 4 & 2 & 14 \\
\hline Enrique GARCÍA MÉROU & 10 & 10.000 & 4 & 2 & 14 \\
\hline Antonio SANTAMARINA & 10 & 10.000 & 4 & 2 & 14 \\
\hline Alejandro SHAW & 10 & 10.000 & 4 & 2 & 14 \\
\hline Alfredo GONZÁLEZ GARAÑO & 10 & 10.000 & 4 & 2 & 14 \\
\hline Andrés BAUSILI & 10 & 10.000 & 4 & 2 & 14 \\
\hline Luís DUHAU & 10 & 10.000 & 4 & 2 & 14 \\
\hline Jacobo SASLAVSKY & 20 & 20.000 & 8 & 4 & 28 \\
\hline Oliverio GIRONDO & 25 & 25.000 & 10 & 5 & 35 \\
\hline Rafael VEHILS & 25 & 25.000 & 10 & 5 & 35 \\
\hline Victoria OCAMPO & 30 & 30.000 & 12 & 6 & 42 \\
\hline Total & 180 & 180.000 & 72 & 36 & 252 \\
\hline
\end{tabular}

La segunda estrategia elegida para conjurar las graves consecuencias que el conflicto bélico internacional auguraba en la economía argentina transformó en los hechos la convivencia de Sudamericana con otras editoriales del país. Comenzó entonces el proceso de adquisición de empresas existentes: la editorial se reunió con los principales accionistas de la Librería del Colegio, Joaquín y Eduardo Cabaut, proponiéndoles una operación que suponía tomar posesión inmediata de esa empresa para colocar a Sudamericana

[...] en excelentes condiciones para editar, a partir de aquel momento, al ritmo que aconsejen las circunstancias, por cuanto de ahora en adelante nuestra sociedad podrá editar con uso gastos generales mínimos, contando, como cuenta, con la organización de la referida Librería ${ }^{62}$.

Esta conversión colocaría a López Llausàs en una posición hegemónica, al decidir tanto la gestión de la editorial como la comercialización de las obras. A aquellas dos estrategias se suma una tercera de más largo aliento que consistió en nutrirse de colecciones distintas para un público también diverso, pero sin potenciar la producción local, ya que en los primeros catálogos se puede comprobar la casi inexistencia

61 Fuente: Plan de reorganización financiera y proyecto de reforma de los Estatutos de la Editorial Sudamericana, Asamblea General Extraordinaria del 25 de junio de 1940, y Carta de Emilio Ravignani a la Editorial Sudamericana SA. Buenos Aires, VI-1940. UBA, Colección Emilio Ravignani, Serie 2, Caja 36, Correspondencia (1914-1952).

62 Carta de la Editorial Sudamericana S.A. a Emilio Ravignani. Buenos Aires, 15-VI-1940. UBA, Colección Emilio Ravignani, Serie 2, Caja 36, Correspondencia (1914-1952). 
de autores argentinos. Así surgieron Sur ${ }^{63}$, Horizonte, Ciencia y Cultura ${ }^{64}$, Brevarios del Pensamiento Filosófico ${ }^{65}$, y la Colección Infantil que incluyó textos de María Rosa Oliver, Julio Rinaldini y Leopoldo Marechal. En el catálogo de 1945, por ejemplo, la Colección Horizonte, dedicada a novelas, incluye entre sus 45 títulos al español Pío Baroja y al argentino Eduardo Mallea, pero el resto son básicamente traducciones ${ }^{66}$.

\section{REFLEXIONES FINALES}

El proyecto empresarial estudiado se inscribe en una tradición de editores y agentes culturales que habían visto en Hispanoamérica el horizonte de sus estrategias comerciales. En esta tradición refulgen con luz propia los hombres de negocios catalanes asociados a la Casa de América de Barcelona, cuya existencia peligró a partir de la Guerra Civil. Sudamericana, por su parte, coincide con la "época de oro" de la industria editorial en Argentina que comprende el periodo de 1938 a 1953. Su origen y desarrollo están directamente ligados al nacimiento de casas de dilatada trayectoria, cuyos recursos humanos y materiales provenían en gran parte de España. En esta etapa el papel desempeñado por los editores catalanes será central: hasta poco antes de la Guerra Civil, las empresas catalanas eran responsables del $70 \%$ de los libros exportados por España y habían gestado un círculo social muy activo y potente. El conflicto bélico español generó un éxodo de hacia América, en especial México y Argentina, y produjo un impacto duradero en la transformación de la industria editorial de ambos países. En Argentina, entre los casos más significativos, destacan las figuras de Gonzalo Losada, Julián Urgoiti, Manuel Olarra, el propio Antoni López Llausàs, Joaquín de Oteyza, Mariano Medina del Río, Arturo Cuadrado, Rafael Ollara Jiménez, Luis Seoane, entre otros, quienes participaron de la creación de casas como Espasa-Calpe Argentina (1937) ${ }^{67}$, Losada (1938, considerada la editorial de los exiliados) ${ }^{68}$, Emecé (1939), Sudamericana (1939).... Pero la Guerra Civil no fue la única causa de este fenómeno: que Gonzalo Losada y Antoni López Llausàs se encontraran en Buenos Aires a fines de los años treinta al frente de algunas de las iniciativas de publicación de libros más ambiciosas, antes que el efecto de la apresurada diáspora republicana (Vehils y Bausili, sin ir más lejos, no pueden ser incluidos en este grupo), era resultado de la confluencia de los pacientes hilos de una red mercantil que se había ido tendiendo sobre los mercados hispanoamericanos desde principios de siglo. La presencia de editores españoles en América, y particularmente en el Cono Sur, había tomado impulso gracias a la acción de un sistema complejo de redes económicas, culturales y políticas. Una trama que se encabalgaba sobre las diferentes tendencias del movimiento americanista y se articulaba con la creación y

63 Esta colección publicó trabajos de Aldous Huxley, Emily Bronte, Oliverio Girondo, Eduardo

Mallea, William Faulkner (Las palmeras salvajes) y Virginia Woolf (Orlando), entre otros.

64 Se publicaría, por ejemplo, El hombre y la cultura de Ruth Benedict.

65 Se incluyeron obras de Kant, Locke, Hume y Descartes.

66 De Diego, 2006, p. 117.

67 Sobre Espasa véase CASTELlano, 2000.

68 GUDIÑo KIEFFER, 2004. 
el fomento de diversas corporaciones patronales no sólo vinculadas con la industria del libro, sino también con el comercio exterior y con la acción de instituciones no oficiales consagradas al estímulo de las relaciones culturales y económicas entre España y sus antiguas colonias ${ }^{69}$.

En manos de españoles, y en el contexto de la debacle de la industria editorial española a partir de 1936, la política comercial de estas empresas estuvo orientada hacia el mercado externo y marcó el rumbo del comercio del libro en los mercados hispanoamericanos hasta mediados de la década de $1950^{70}$. En la década de 1940, la Sudamericana que entonces ya dirigía de manera hegemónica López Llausàs en Buenos Aires aún mantenía los rasgos de las políticas culturales y comerciales que los editores catalanes habían diseñado a principios de siglo. Esto es, énfasis en las traducciones al confeccionar el catálogo y una especial atención a los mercados hispanoamericanos considerados como una suma de mercados nacionales. En los años que siguieron a la Guerra Civil, aprovechando el repliegue acentuado de las empresas españolas en los primeros años del franquismo, Sudamericana apuntó hacia el mercado externo al que procuraba abastecer de traducciones al castellano ${ }^{71}$. Cuando a mediados de los años cincuenta la industria peninsular recuperó lentamente sus antiguas plazas y el resto de las repúblicas hispanoamericanas comenzaron a consolidarse en la producción de libros, Sudamericana fue prestando mayor atención al mercado interno, lo que explica la creciente inclusión de autores nacionales en su catálogo. Así, se convirtió en una empresa asociada a la consolidación del nuevo "Parnaso" literario latinoamericano de los sesenta, al incluir a autores significativos como Ernesto Sábato, Julio Cortázar, Manuel Mujica Lainez, Manuel Puig, Silvina Bullrich, Gabriel García Márquez, entre otros, cuando Francisco Porrúa y Enrique Pezzoni se incorporaron como directores literarios. Para España, la utopía editorial que Gutiérrez Jiménez había formulado en 1892, y que en los años siguientes fue puesta en marcha por Renacimiento, Salvat, Sopena, Montaner y Simon, Espasa Calpe y CIAP hasta su colapso durante la Guerra Civil, recién recuperó su vitalidad en la década de 1960. Luego de una larga sombra, a fines de la década de 1950 las editoriales españolas, y en especial las catalanas o establecidas en Barcelona,-contaron con una nueva oportunidad para colocarse a la vanguardia del mundo de la publicación de libros de habla hispana. Al amparo de una relativa apertura económica y cultural, por ejemplo, Seix Barral encabezó un proceso de modernización profunda del sector, convirtiendo a un conjunto notable de escritores hispanoamericanos en un éxito de ventas sin precedentes en el nivel de la literatura culta y de experimentación formal72. Más allá de la innegable calidad de esta nueva literatura, la política edito-

69 EsPÓsITo, 2010.

70 De DIEGO, 2006, pp. 111-145.

71 Carta de la Editorial Sudamericana S.A. a Emilio Ravignani. Buenos Aires, 8-VI-1940 (incluye el catálogo de la Editorial Sudamericana de 1940). UBA, Colección Emilio Ravignani, Serie 2, Caja 36, Correspondencia (1914-1952).

72 Al Premio Biblioteca Breve otorgado a La ciudad y los perros de Mario Vargas Llosa en 1962 le sucedieron una serie de éxitos editoriales que hicieron que la nueva narrativa latinoamericana trascendiera las barreras del idioma y también las barreras continentales; véase entre otros, EsPosito, 2009. 
rial de nuevo cuño posibilitó que un buen número de narradores hispanoamericanos trascendiera sus fronteras nacionales para convertirse en autores de renombre en todo el continente. Hizo, además, que el castellano adquiriera importancia como lengua de traducción en los mercados europeos del libro a partir de su estrecha vinculación con empresas como Einaudi o Gallimard.

La producción y comercialización, así como la disputa proteccionista de carácter asociativo o corporativo en torno a la protección de una mercancía tan particular como es el libro, permiten observar a los editores como negociantes y, al mismo tiempo, ayudan a aplicar una perspectiva histórica y comparada para entender las fluctuaciones empresariales. Negociantes y empresarios que nutren el mundo editorial ameritan el abordaje de las variaciones del mercado así como las adaptaciones de las redes mercantiles para hacer frente a las exigencias de innovación de las empresas productoras de libros. En el caso estudiado aquí, al calor del movimiento americanista surgido con la conmemoración del Primer Centenario de las Independencias se promocionó durante las tres décadas siguientes una comunidad de intereses específicamente empresariales que contribuyeron, a partir de 1939, a definir alternativas a la salida franquista, en muchos casos garantizando un lugar laboral a algunos exiliados o abriendo un campo de acción a empresarios y publicistas que vieron cercenadas sus expectativas en España. En este sentido, Sudamericana es un resultado, aunque no lineal, de los vínculos desplegados por grupos económicos a uno y otro lado del Atlántico y una alternativa a la clausura de experiencias de envergadura actualizadas en otros contextos. Las diversas apreciaciones que dejaron los actores sobre las posibilidades abiertas al mercado del libro escrito en español y esparcido entre la península y el continente americano, dieron cuerpo también a ensayos tales como asociaciones (Casa de América de Barcelona), revistas americanistas (Mercurio), corporaciones patronales (Centro de la Propiedad Intelectual o la Cámara del Libro de Barcelona) y editoriales diversas, cuyo estudio contribuye a entender el éxito o el fracaso de algunos emprendimientos específicos, así como el de los recorridos individuales de quienes los proyectaron y ejecutaron.

\section{6.- REFERENCIAS BIBLIOGRÁFICAS}

ABellán, José Luis

1983 De la Guerra Civil al exilio republicano (1936-1939). Madrid. Editorial Mezquita.

Almonacid Zapata, Fabián

2004 "Españoles en Chile: reacciones de la colectividad frente a la República, Guerra Civil y Franquismo (1931-1940)". Revista Complutense de Historia de América. Madrid. no 30, pp. 149-185.

AsAmblea NACIONAL DE Editores y LiBRERos

1909 Crónica de la Primera Asamblea Nacional de Editores y Libreros. Barcelona. Imprenta Elzeviriana.

1911 Segunda Asamblea Nacional de Editores y Libreros: memoria é informes. Valencia. Sémpere. 
ASOCIACIÓN DE ESCRITORES Y ARTISTAS ESPAÑOLES

1893 Congreso Literario Hispanoamericano: 31 de octubre al 10 de noviembre de 1892. Madrid. Establecimiento Tipográfico de Ricardo Fé.

AUBERT, Paul

2005 "Crisis del papel y consecuencias de la industrialización de la prensa (1902-1931)". En Desvois-Chaput, pp. 73-90.

BAUSILI SANROMÀ, Andrés

1974 Cambó y el desarrollo. Acontecer económico en su época y en el mundo contemporáneo. Buenos Aires. Publicaciones de la Institución Cultural Española.

BERENGUER CARISOMO, Arturo

1953 España en la Argentina: ensayo sobre una contribución a la cultura nacional. Buenos Aires. Artes Gráficas Bartolomé Chiesino.

Bernasconi, Alicia - Frid, Carina (eds.)

2006 De Europa a las Américas: dirigentes y liderazgos, 1880-1960. Buenos Aires. CEMLA-Biblos-CEHIPE.

BeretTa Curi, Alcides

1993 "El proyecto imperial de la burguesía catalana para la América Latina, 1898-1931”. En D’ElíA, Germán y otros. España y América Latina en el siglo XX. Montevideo. Universidad de la República, pp. 15-135.

Bernabeu Albert, Salvador

1987 1892: el IV Centenario del descubrimiento de América en España: coyuntura y conmemoración. Madrid. CSIC.

2007 "Los americanistas y el pasado de América: tendencias e instituciones en vísperas de la Guerra Civil". Revista de Indias. Madrid. vol. 67. ${ }^{\circ}$ 239, pp. 251-282.

BOTREL, Jean François

1993 Libros, Prensa y Lectura en la España del siglo XIX. Madrid. Fundación Germán Sánchez Ruipérez.

2003 "Gaspar i Roig et le rêve des editeurs espagnols (1845-1861)". En Andréani, Roland - Michel, Henri - Pélaquie, Élie (comps.). Des Moulins à papier aux bibliothèques: le livre dans la France méridionale et l'Europe méditerranéenne: XVIe-XXe siècles. Actes du colloque tenu les 26 et 27 mars 1999 à l'Université Montpellier III. Montpellier. Université Paul-Valéry Montpellier III.

CABRERA, Mercedes

1994 La industria, la prensa y la política. Nicolás María de Urgoiti. Madrid. Alianza.

Cagiao, Pilar (coord.)

2004 Cien anos da Biblioteca América (1904-2004). Santiago de Compostela. Universidad de Santiago de Compostela.

CAGiaO, Pilar - Rey Tristán, Eduardo (eds.)

2005 Aproximaciones al americanismo entre 1892 y 2004: proyectos, instituciones y fondos de investigación. Santiago de Compostela. Universidad de Santiago de Compostela. 
CALZADA, Rafael

1926 Cincuenta años de América: notas autobiográficas. Obras Completas. T. IV. Vol. 1. Buenos Aires. Librería y Casa Editora de Jesús Menéndez.

CÁmara Oficial del Libro de BARCELONA

1922 Memoria de la Cámara Oficial del Libro de Barcelona correspondiente al ejercicio 1921-1922. Barcelona. Imprenta Mercantil.

1923 Memoria de la Cámara Oficial del Libro de Barcelona correspondiente al ejercicio 1922-1923. Barcelona. Imprenta Mercantil.

1925 Memoria de la Cámara Oficial del Libro de Barcelona correspondiente al ejercicio 1923-1924. Barcelona. Imprenta Mercantil.

Castellano, Philippe

2000 Espasa, una aventura editorial. Madrid. Espasa.

2005 "La distribución de libros en Latinoamérica en vísperas de la Primera Guerra Mundial”. En Desvois-Chaput, pp. 97-108.

Ceballos Viro, Álvaro

(en prensa) Ediciones alemanas en español (1850-1900). Madrid-Frankfurt. Iberoamericana-Vervuert.

Costa Ruibal, Òscar

2002 L'Imaginari Imperial. El noucentisme català i la politica internacional. Barcelona. Institut Cambó/Alpha.

DALla CORTE, Gabriela

2005 Casa de América de Barcelona (1911-1947). Comillas, Cambó, Gili, Torres y mil empresarios en una agencia de información e influencia internacional. Madrid. LID Editorial Empresarial.

2006 "Empresas, instituciones y red social: la Compañía Hispanoamericana de Electricidad (CHADE) entre Buenos Aires y Barcelona". Revista de Indias. Madrid. vol. LXVI. no 237, pp. 519-544.

2009 Lealtades firmes. Redes de sociabilidad y empresas: la Carlos Casado S. A. entre la Argentina y el Chaco paraguayo (1860-1940). Madrid, CSIC.

(en prensa) "La recomposición del vínculo entre América y España: entre la celebración y el diálogo en el primer Centenario de Independencias (1908-1910)". En Navarro Azcue, Concepción - LuQue Talaván, Miguel - AMADORI, Arrigo (eds.). Una crisis atlántica: España, América y los acontecimientos de 1808. Madrid. Asociación Española de Americanistas. Universidad Complutense de Madrid.

Dalla Corte, Gabriela - Prado, Gustavo

2006 "Luces y sombras de dos paradigmas del americanismo español en la renovación del diálogo hispanoamericano (1909-1912)". Anuario de Estudios Americanos. Sevilla. vol. 63. n 2, pp. 195-216.

De Diego, José Luis (dir.)

2006 Editores y políticas editoriales en Argentina (1880-2000). Buenos Aires. Fondo de Cultura Económica. 
De RiQuer I PERMANYer, Borja

1997 El último Cambó (1936.1947). La tentación autoritaria. Barcelona. Grijalbo.

Desvois, Jean Michel - Chaput, Marie Claude (coords.)

2005 Prensa, impresos, lectura en el mundo hispánico contemporáneo: homenaje a Jean François Botrel. Bordeaux.

DOMINGo ACEBRón, María Dolores

2005 Rafael María de Labra: Cuba, Puerto Rico, las Filipinas, Europa y Marruecos en la España del Sexenio Democrático y la Restauración (1871-1918). Madrid. CSIC.

EsPósito, Fabio

2009 "Seix Barral y el "Boom" de la nueva narrativa hispanoamericana: las mediaciones culturales de la edición española". Orbis Tertius. La Plata. $\mathrm{n}^{\mathrm{o}}$ 15. En línea: http://www.orbistertius.unlp.edu.ar/numeros/numero15/03.\%20Esposito.pdf.

2010 "Los editores españoles en Argentina: antecedentes de un desembarco. Redes comerciales, políticas y culturales entre España y Argentina (1892-1938)". En Altamirano, Carlos (dir.). Entre cultura y política: historia de los intelectuales en América Latina. Buenos Aires. Katz Editores, pp. 59-90.

FERNÁNDEZ RODRÍGUEZ, Pura

1998 "El monopolio del mercado internacional de impresos en castellano en el siglo XIX: Francia, España y la 'ruta' de Hispanoamérica". Bulletin Hispanique. Bordeaux. t. 100. $\mathrm{n}^{\mathrm{o}}$ 1, pp. 165-190.

http://dx.doi.org/10.3406/hispa.1998.4964

1999 "La editorial Garnier y la difusión del patrimonio bibliográfico en castellano". Tes philies tade dora. Miscelánea léxica en memoria de Conchita Serrano. Madrid. CSIC, pp. 603-612.

FERNÁNDEZ, Sandra

2006 "Sociabilidad, corporaciones e instituciones". En BARRIERA, Darío (dir.). Nueva Historia de Santa Fe. Tomo 7. Rosario. Prohistoria-La Capital, pp. 13-26.

GILI, Gustavo

1917 Cámara del Libro Español. Proyecto para la Asociación de los Amigos del Libro. Barcelona. Dirección Interina.

GONZÁLEZ MARTíNEZ, Evangelina

1992 "Españoles en un país más allá del Océano. Notas acerca de las etapas de la emigración". Revista de Indias. Madrid. vol. LII. nº 195-196, pp. 515-527.

GUDIÑo KIEFFER, Eduardo

2004 Losada: Gonzalo Losada, el editor que difundió el libro argentino en el mundo. Buenos Aires. Dunken.

GuTIÉRREZ JiMÉNEZ, Rafael

1893 La producción literaria en España y el comercio de exportación de libros a América y documentos del Congreso Literario de 1892. Madrid. Imprenta de Manuel Tello. 
HORTELANO, Benito

1936 Memorias. Madrid. Espasa Calpe.

INFANTES, Víctor - LóPEZ, Francois - BOTREL, Jean François

2003 Historia de la edición y la lectura en España (1472-1914). Madrid. Fundación Germán Sánchez Ruipérez.

LARRAZ ELORRIAGA, Fernando

2007 "Los editores españoles ante los mercados de lectura americanos" (1900-1939)". Cuadernos Americanos. México. Nueva época. vol. 1. no 119 , pp.131-150.

LÓPEZ LLOVET, Gloria

2004 Sudamericana. Antonio López Llausás, un editor con los pies en la tier$r a$. Buenos Aires. Dunken.

2006 "Pasaban las vacaciones en Punta del Este y Mar del Plata. Tenían una vida muy de relación con la gente de aquí". En Guillamón, Julià (dir.). Literaturas del exilio. Barcelona. Sociedad Estatal para la Acción Cultural Exterior de España, pp. 83-91.

LLANAS, Manuel

2005 L'Edició a Catalunya: el segle XX (fins a 1939). Barcelona. Gremi d'Editors de Catalunya.

MARTínez MARTín, Jesús

1991 Lectura y lectores en el Madrid del siglo XIX. Madrid. CSIC.

Martínez Martín, Jesús - Martínez Rus, Ana - SÁnchez García, Raquel

2004 Los patronos del libro. Las asociaciones corporativas de editores y libreros. Gijón. Trea.

MARTínez Rus, Ana

2000 "La proyección editorial en los mercados americanos (1901-1936)". Pliegos de Bibliofilia. Madrid. $\mathrm{n}^{\circ}$ 12, pp. 31-53.

2002 "La industria editorial española ante los mercados americanos". Hispania. Madrid. vol. LVIII. no 212, pp. 1025-1031.

2003 La política del libro durante la segunda república. Socialización de la lectura. Gijón. Trea.

2008 "Exportando cultura: las estrategias transatlánticas de los editores españoles, 1892-1936". Revista de la Historia de la Economía y de la Empresa. Bilbao. Año II. nº 2, pp. 183-204.

Moya, José Carlos

1998 Cousins and Strangers: Spanish Immigrants in Buenos Aires, 18501930. California. University of California Press.

NARANJo Orovio, Consuelo

2007 "Los caminos de la JAE en América Latina: redes y lazos al servicio de los exiliados republicanos". En Monográfico La Junta para Ampliación de Estudios y América Latina: Memoria, políticas y acción cultural (19071939). Revista de Indias. Madrid. vol. LXVI. nº 239, pp. 283-306.

Naranjo Orovio, Consuelo - Puig-Samper, Miguel Ángel - Luque, María Dolores 2002 Los lazos de la cultura. El Centro de Estudios Históricos de Madrid y la Universidad de Puerto Rico, 1916-1939. Madrid. CSIC. 
NúÑEZ SEIXAS, Xosé Manuel

1999 "Asociacionismo local y movilización sociopolítica: notas sobre los gallegos en Buenos Aires (1890-1933)". En FERnÁndEZ, Alejandro MoyA, José Carlos (eds.). La inmigración española en Argentina. Buenos Aires. Biblos, pp. 195-233.

2001 La Galicia Austral. La inmigración gallega en la Argentina. Buenos Aires. Biblos.

Pellegrino SoARes, Gabriela

2007 "Novos meridianos da produção editorial em castelhano: o papel de espanhóis exilados pela Guerra Civil na Argentina e no México". Varia História. Belo Horizonte. vol. 23. nº 38, pp. 77-96.

Prado, Gustavo H.

2008 Rafael Altamira en América (1909-1910). Historia e Historiografía del proyecto americanista de la Universidad de Oviedo. Madrid. CSIC.

QuIJADA, Mónica

1991 Aires de República, Aires de Cruzada: la Guerra Civil Española en Argentina. Barcelona. Sendai.

RAMA, Carlos

1982 Historia de las relaciones culturales entre España y América: siglo $X I X$. México. Fondo de Cultura Económica.

RAHOLA I TRÈMOLS, Frederic

1909 "Eslabonando". Revista Comercial Iberoamericana Mercurio. Barcelona. Año IX. Tomo 8. nº 91, p. 1950.

RIBES, Frederic

2008 "Rafael Vehils i la aposta americana de Cambó". Revista de Catalunya. Barcelona. $n^{\circ} 239$, pp. 20-28.

RIERA I SANS, Pablo

1901 "Influencia del Instituto Catalán en las Artes del Libro". Revista Gráfica. Barcelona. Año 1, nº 1, p. 4.

SAMPERE, Antonio

1998 Historia de la Cámara Española de Comercio de la República Argentina. Buenos Aires. Cámara Española de Comercio en Buenos Aires.

SCHWARSTEIN, Dora

2001 Entre Franco y Perón, Memoria e identidad del exilio republicano español en Argentina. Barcelona. Crítica.

SEPÚlVEDA MuÑoz, Isidro

1991 "Medio siglo de asociacionismo americanista español, 1885-1936". Espacio, Tiempo y Forma. Madrid. Tomo IV, pp. 271-290.

1994 Comunidad cultural e hispano americanismo (1885-1936). Madrid. UNED.

SOPENA, Ramón

1929 Una visita a la editorial Ramón Sopena. Lo que puede hacerse en treinta años de trabajo. Barcelona. Sopena. 
UCELAY DA CAL, Enric

2003 El Imperialismo catalán: Prat de la Riba, Cambó, D’Ors y la conquista moral de España. Barcelona. Edhasa.

VÉLEZ, Palmira

2007 La historiografía americanista en España, 1755-1936. Madrid. Editorial Iberoamericana-Vervuert.

VEHILS, Rafael

1909 "América en España: la Casa de América". Revista Comercial Iberoamericana Mercurio. Barcelona. Año IX. Tomo 8. nº 97, p. 2143.

1927 El libro en el Uruguay: la industria editorial, el libro español, el libro de texto, el régimen de propiedad intelectual. Informe del Delegado de la Cámara de Comercio de Montevideo Rafael Vehils a la Conferencia Nacional del Libro. Barcelona. Imprenta de L. Cortina.

1917-1919 Delegación Parlamentaria para las Relaciones con América y Unión Interparlamentaria Hispanoamericana, diputado a Cortes por Castelltersol. Barcelona. Revista Comercial Iberoamericana Mercurio y Casa de América Asociación Internacional Iberoamericana.

YÁÑEZ GALlaRdo, César

1985 El americanismo de la burguesía catalana, 1898-1929: un proyecto imperialista. Tesis de Licenciatura. Bellaterra. Universidad Autónoma de Barcelona. Mimeo. 